\title{
Air-sea interaction and formation of the Asian summer monsoon onset vortex over the Bay of Bengal
}

\author{
Guoxiong Wu • Yue Guan • Yimin Liu • \\ Jinghui Yan $\cdot$ Jiangyu Mao
}

Received: 4 July 2010/Accepted: 19 December 2010/Published online: 4 January 2011

(C) The Author(s) 2010. This article is published with open access at Springerlink.com

\begin{abstract}
In spring over the southern Bay of Bengal (BOB), a vortex commonly develops, followed by the Asian summer monsoon onset. An analysis of relevant data and a case study reveals that the BOB monsoon onset vortex is formed as a consequence of air-sea interaction over BOB, which is modulated by Tibetan Plateau forcing and the land-sea thermal contrast over the South Asian area during the spring season. Tibetan Plateau forcing in spring generates a prevailing cold northwesterly over India in the lower troposphere. Strong surface sensible heating is then released, forming a prominent surface cyclone with a strong southwesterly along the coastal ocean in northwestern BOB. This southwesterly induces a local offshore current and upwelling, resulting in cold sea surface temperatures (SSTs). The southwesterly, together with the near-equatorial westerly, also results in a surface anticyclone with descending air over most of BOB and a cyclone with ascending air over the southern part of BOB. In the eastern part of central BOB, where sky is clear, surface wind is weak, and ocean mixed layer is shallow, intense solar radiation and low energy loss due to weak surface latent and sensible heat fluxes act onto a thin ocean layer,
\end{abstract}

G. Wu $(\bowtie) \cdot$ Y. Guan · Y. Liu · J. Mao

State Key Laboratory of Numerical Modeling for Atmospheric

Sciences and Geophysical Fluid Dynamics (LASG),

Institute of Atmospheric Physics, Chinese Academy of Sciences,

P.O. Box 9804, 100029 Beijing, China

e-mail: gxwu@lasg.iap.ac.cn

Y. Guan

Graduate University of Chinese Academy of Sciences,

100039 Beijing, China

J. Yan

National Climate Center, China Meteorological Administration, 100080 Beijing, China resulting in the development of a unique BOB warm pool in spring. Near the surface, water vapor is transferred from northern $\mathrm{BOB}$ and other regions to southeastern BOB, where surface sensible heating is relatively high. The atmospheric available potential energy is generated and converted to kinetic energy, thereby resulting in vortex formation. The vortex then intensifies and moves northward, where SST is higher and surface sensible heating is stronger. Meanwhile, the zonal-mean kinetic energy is converted to eddy kinetic energy in the area east of the vortex, and the vortex turns eastward. Eventually, southwesterly sweeps over eastern BOB and merges with the subtropical westerly, leading to the onset of the Asian summer monsoon.

Keywords Air-sea interaction · Upwelling · BOB warm pool $\cdot$ Vortex $\cdot$ Monsoon onset

\section{Introduction}

The Asian monsoon seasonal transition from winter to summer in East and South Asia is characterized by abrupt changes in the general circulation. Ananthakrishnan et al. (1981) pointed out that the summer monsoon onset over the southeast Bay of Bengal (BOB) starts toward the end of April, earlier than any land monsoon onset. Recent studies have also proposed that the earliest onset of the Asian summer monsoon occurs in BOB, following by the onset over South China Sea (SCS), and lastly over India (e.g., Lau and Yang 1997; Wu and Zhang 1998; Mao et al. 2002a; Mao and Wu 2007). Associated with the Indian summer monsoon onset is a type of low-level vortex known as the onset vortex (Krishnamurti et al. 1981), which is formed at around $10^{\circ} \mathrm{N}$ in the Bay of Bengal 
(BOB) and east of the Arabian Sea (Ananthakrishnan et al. 1968). The vortex moves northward and generally develops rapidly into a tropical storm, resulting in a region of convergence and subsequent strengthening of the westerly to its south. In turn, the enhanced westerly leads to the Indian monsoon onset and advances northward with the onset vortex (Vinayachandran et al. 2007). Many previous studies have described features of the vortex, including the distribution of precipitation and the vortex structure (e.g., Pisharoty and Asnani 1957; Rao and Rajamani 1970; Sharma and Srinivasan 1971). Subsequent studies suggested that barotropic instability associated with horizontal wind shear leads to the formation of the vortex, and that diabatic heat supplies the energy to the vortex required for its development (Krishnamurti 1981, 1985; Krishnamurti and Ramanathan 1982; Krishnamurti et al. 1981). Mak and Kao (1982) found that vertical wind-shear and baroclinic instability play an important role in the development of the vortex.

The onset vortex is also influenced by the boundary condition connected with the local sea surface temperature (SST) (Joseph 1990). As is well known, atmospheric convection in the tropics is highly sensitive to SST and to fluctuations in surface flux of the underlying ocean. SST above $28^{\circ} \mathrm{C}$, in combination with other factors, is necessary to produce organized deep convection in the tropical atmosphere (Gray 1968, 1975, 1998; Harr and Chan 2004). In the Indian Ocean, warm SST is generally found in three locations (Vinayachandran et al. 2007): the western equatorial Indian Ocean, the southeastern Arabian Sea (SEAS), and eastern BOB, with the latter being warmest during April. At about 1 week before the Indian monsoon onset, a warm pool $\left(\mathrm{SST}>30.5^{\circ} \mathrm{C}\right)$ exists over the Arabian Sea (Seetaramayya and Master 1984). The warm SST in the SEAS leads to the formation of a vortex that affects the Indian monsoon onset over Kerala in early June (Joseph 1990; Shenoi et al. 1999, 2005). Furthermore, Rao and Sivakumar (1999) reported that the onset vortex generally forms over this region because it is related to the location of the maximum heat content in the upper layer of the tropical ocean, as this is a potential energy source for the vortex. Furthermore, by use of numerical experiments, Kershaw (1985, 1988) demonstrated that the use of anomalies or accurate SST data results in more accurate predictions of summer monsoon onset than the use of climatological SST.

Most of the above studies focused on the Arabian Sea onset vortex. Actually the BOB monsoon onset in early May is also influenced by the development of the onset vortex in BOB (Lau et al. 1998; He and Shi 2002; Liu et al. 2002; Yan 2005). This onset vortex moves northward over the BOB area, splitting the ridge of the subtropical high and leading to the monsoon onset. Yan (2005) proposed a physical mechanism for interpreting the eastward advance of the Asian monsoon onset from BOB to the South China Sea (SCS). Vinayachandran et al. (2007) discussed the structure of the onset vortex, reporting that the warmest SST is formed earliest over eastern BOB, which is then followed by the BOB monsoon onset.

Despite these advances, many important and basic questions remain unanswered concerning the BOB monsoon onset, including how the warm SST is formed over BOB in spring, how it influences and interacts with the BOB monsoon onset vortex, and where the energy required for the vortex genesis comes from since either barotropic or baroclinic instability merely explains the energy conversion within the atmosphere. In this context, the present study analyzes observational data related to air-sea interaction in BOB in the spring of 2003, and investigates how this interaction contributed to the formation of a spring warm pool in the eastern part of central $\mathrm{BOB}$ and to the development of a vortex that occurred from May 8 to 19, which led to the Asian summer monsoon onset.

The remainder of the manuscript is organized as follows. Section 2 descripts the data used in this study. Section 3 outlines the general behavior of the BOB monsoon onset vortex and its connection with the seasonal transition from winter to summer. Section 4 considers the formation and development of the vortex under a special circulation pattern over BOB for the year 2003. Also examined is the oceanic influence on vortex development and the energy transformation associated with evolution of the vortex. Section 5 examines how the spring BOB warm pool is formed, and how SST in BOB evolves before and after formation of the vortex. For this purpose, we calculate the energy budget in the mixed layer, including surface net radiation, heat flux, and cold entrainment due to mixing. In Sect. 6, we investigate the influence of the vortex on the Asian summer monsoon onset. Finally, a summary and discussion are provided in Sect. 7.

\section{Data description}

This study analyzed the following datasets: (1) daily global sea-surface pressure with a resolution of $1.125^{\circ}$ latitude $\times 1.125^{\circ}$ longitude, from the reanalysis of the European Centre for Medium-Range Forecasts (ECMWF) (ERA-40, Uppala et al. 2005); (2) daily global sea-surface winds with a high horizontal resolution of $0.25^{\circ}$ latitude $\times 0.25^{\circ}$ longitude, from the National Oceanic and Atmospheric Administration (NOAA) (Zhang et al. 2006) and National Climatic Data Center (NCDC) (Smith and Reynolds 2004), for which wind speeds are generated by blending observations from six satellites and for which wind directions from the National Center for Environment 
Prediction (NCEP) Reanalysis 2 (NRA-2) (Kanamitsu et al. 2002) are interpolated into the blended speed grids; (3) daily optimum interpolation SST (OISST) analysis data (AVHRR + AMSR-E products) from the NOAA Satellite and Information Service with the same resolution as sea surface winds and weekly OISST with horizontal resolution of $1^{\circ}$ latitude $\times 1^{\circ}$ longitude; (4) daily SST, ocean latent heat flux, sensible heat flux, net radiation flux, longwave and shortwave radiation at the sea surface with a resolution of $1^{\circ}$ latitude $\times 1^{\circ}$ longitude obtained from the Objectively Analyzed Air-Sea Fluxes (OAFlux) for the Global Oceans, sponsored by the Woods Hole Oceanographic Institution (WHOI) Cooperative Institute for Climate and Ocean Research (CICOR); and (5) pentad total downward heat flux at the surface, ocean current, salinity, mixed-layer depth,and potential temperature profiles $\left(1 / 3^{\circ}\right.$ latitude by $1^{\circ}$ longitude, 40 levels) taken from the NCEP Global Ocean Data Assimilation System (GODAS) (Ji et al. 1995) for accurate air-sea processes. Because OAFlux only provides heat flux data over the sea, we also employed daily diabatic heating and wind data at 10-m height and at various pressure levels from NCEP/NCAR Reanalysis 1 to analyze the temporal variations in land heating.

The vortex records are retrieved from the tropical cyclone Best Track Data from 1979 to 2009, as archived at the Joint Typhoon Warning Center (JTWC). This dataset provides data on cyclone category for the period after 2000 , but not before. To overcome the period limitation on cyclone category in the Best Track Data, we use the "maximum sustained wind speed in knots" provided by JTWC to determine the vortex category, with reference to the Saffir-Simpson Hurricane Scale (see Table 1). Using this approach, the vortex categories prior to 2000 are determined on a daily basis.

\section{Climatology: BOB vortex and seasonal transition from winter to summer}

In spring of most years, a vortex develops over southern BOB, subsequently moving northward and followed by the Asian summer monsoon onset over eastern BOB. This vortex is generally referred to as the BOB monsoon onset vortex (Lau et al. 1998). Figure 1 shows the tracks of the BOB monsoon onset vortex from 1979 to 2009. The monsoon onset date is defined as the time when the meridional temperature gradient $(\partial T / \partial y)$ in the upper troposphere (between 500 and $200 \mathrm{hPa}$ ) changes from negative to positive, as proposed by Mao et al. (2002b). The monsoon onset vortex and its track are defined according to the following principle: if and only if the cyclone is formed before the BOB monsoon onset and if its life cycle covers the onset time, then the tropical cyclone is defined as the BOB monsoon onset vortex, and the corresponding tropical cyclone track is defined as the vortex track. According to this principle, the $\mathrm{BOB}$ monsoon onset vortex is sought for each year, and the dates of the BOB Asian summer monsoon onset for years in which a monsoon onset vortex developed is listed in Table 2. Only two monsoon onset vortexes were identified for the period before the 1990s, mainly due to a lack of tropical cyclone data. For the period after 1990, 13 onset vortexes are identified from the 20year record. In other words, the strong BOB monsoon onset vortex occurs in most years, at least for the period after 1990. The corresponding tracks of the onset vortexes are shown in Fig. 1, revealing the following common features:

1. All the onset vortexes originate in southern BOB, south of $10^{\circ} \mathrm{N}$.

2. All the vortexes move northward before turning northeastward in northern BOB (north of $15^{\circ} \mathrm{N}$ ), except in 1979 and 1990 when the onset vortex rapidly developed into a typhoon after crossing $10^{\circ} \mathrm{N}$ and then moved northwestward to make landfall over the east coast of India.

3. All the onset vortexes became tropical storms or typhoons upon landfall.

4. Most of the vortexes occurred in late April and early May, in accordance with the BOB monsoon onset.

By searching the low geopotential height centers at 850 and $700 \mathrm{hPa}$ surfaces before the monsoon onset, the monsoon onset vortex can also be identified from NCEP/ NCAR reanalysis data, yielding similar features to those listed above (Yan 2005).

The monsoon is considered a response of the land-sea thermal contrast to the seasonal march of the solar angle (e.g., Webster et al. 1998). In tropical Asia during winter, cold land is located to the north and the warm Indian Ocean to the south; whereas in summer, warm land is located to the north and colder ocean to the south. Therefore, the meridional temperature gradient is reversed during the change in season.

Table 1 Categories of monsoon onset vortex based on the Saffir-Simpson Hurricane Scale and using the "maximum sustained wind speed in knots" provided by JTWC

\begin{tabular}{lllllll}
\hline Category & Super typhoon & Typhoon & Tropical storm & Tropical depression & Tropical cyclone & Disturbance \\
\hline Abbreviation & ST & TY & TS & TD & TC & DB \\
Maximum wind speed $V$ in knots & $\geq 136$ & $\geq 64$ & $64>V \geq 34$ & $34>V$ & $34>V$ & $34>V$ \\
\hline
\end{tabular}


Fig. 1 Tracks of the BOB summer monsoon onset vortex from JTWC a before 2000 and b after 2000. For each track, different categories of vortex (i.e., ST, TY, TS, TD, TC, and DB; see Table 1) are indicated by line color. The year of each onset vortex (listed in Table 2) is marked by the number at each end of each track. Numbers along each track denote the dates of vortex activity; black and white dots along each track denote 0000 and 1200 UTC, respectively

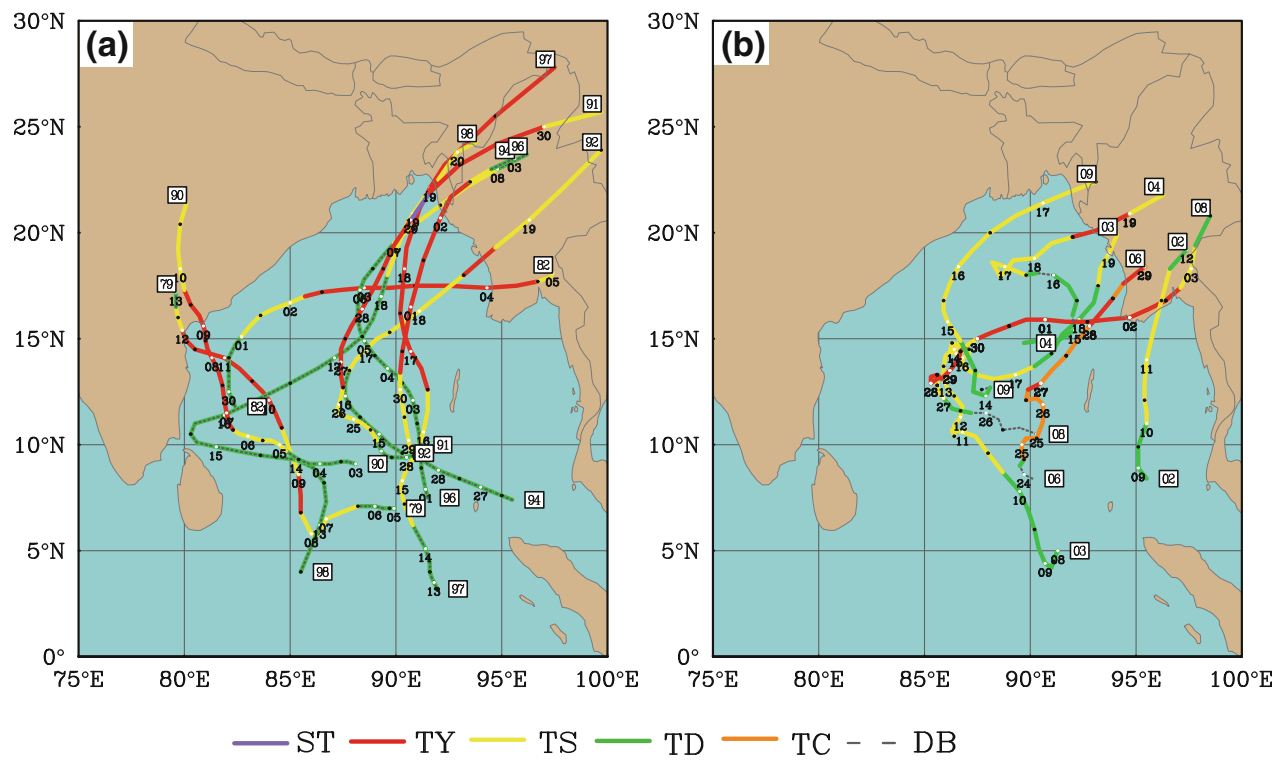

0000 UTC Position $\bigcirc 1200$ UTC Position/Date 3 Tropical Cyclone year

Table 2 Dates of the BOB Asian summer monsoon onset for years in which a monsoon onset vortex developed

\begin{tabular}{|c|c|c|c|c|c|c|c|c|c|c|c|c|c|c|c|}
\hline Year & 1979 & 1982 & 1990 & 1991 & 1992 & 1994 & 1996 & 1997 & 1998 & 2002 & 2003 & 2004 & 2006 & 2008 & 2009 \\
\hline
\end{tabular}

$\mathrm{Li}$ and Yanai (1996) used the upper tropospheric temperature difference between $30^{\circ} \mathrm{N}$ and $5^{\circ} \mathrm{N}$ as an index with which to measure the seasonal transition in the Asian area, and Webster and Yang (1992) used the zonal wind difference between 850 and $200 \mathrm{hPa}$ as an index with which to study the monsoon onset. These two indexes are similar in terms of describing the meridional thermal contrast, due to the constraint of the following thermal wind relation:

$\frac{\partial u}{\partial z} \propto-\frac{\partial T}{\partial y}$.

Note that in south Asia $\left(5^{\circ}-20^{\circ} \mathrm{N}\right)$ during winter, there exists a zonally orientated ridgeline of high pressure at every level. The tropical easterlies exist to the south of this ridgeline, whereas the subtropical westerlies prevail to the north. Vertical tilting of the ridgelines at different levels is consistent with the local vertical shear of zonal wind, and can be used as a measure of the meridional thermal contrast (Mao et al., 2002a, 2004). Before the Asian monsoon onset, $\partial T / \partial y<0, \partial u / \partial z>0$, and the ridgelines tilt southward with increasing height. After the monsoon onset, $\partial T / \partial y>0, \partial u / \partial z<0$, and the ridgelines tilt northward with height. In other words, the ridgelines always tilt toward the warmer region with increasing height, and the moment when the ridgelines become vertical (indicating $\partial T / \partial y=0$ ) is the timing of monsoon onset in the region.

Figure 2 shows the evolution, from April 30 to May 14, of the climate-mean distributions of the ridgelines at 700 ,
500, and $200 \mathrm{hPa}$ (Fig. 2a-c, respectively), and of the relative vorticity at $700 \mathrm{hPa}$ (Fig. $2 \mathrm{~d}-\mathrm{f}$ ). The data used for the analysis are from the NCEP/NCAR reanalysis averaged from 1979 to 2003. By the end of April, the ridgelines over the Asian sector generally show a southward tilt with height (Fig. 2a), representing a typical winter pattern. In early May (Fig. 2b), while the ridgelines still tilt southward with height over most areas, they tilt northward over eastern BOB, representing a summer pattern (Fig. 2b) and indicating that the summer monsoon onset happened in the region. Such a rapid seasonal transition occurs with breaking of the ridgeline at $700 \mathrm{hPa}$. By mid-May (Fig. 2c), the ridgeline at $500 \mathrm{hPa}$ also breaks throughout the region. While tilting of the ridgeline maintains a winter pattern over Saudi Arabia, the Arabian Sea, India, and the Western Pacific, it takes a summer pattern over eastern $\mathrm{BOB}$ and the Indochina Peninsula, where the summer monsoon onset has already occurred.

To reveal the mechanism responsible for breaking of the ridgeline over eastern BOB in early May, Fig. 2d-f shows the stream field and relative vorticity at $700 \mathrm{hPa}$. Before the BOB monsoon onset, a cyclonic flow exists south of the Tibatan Plateau, anticyclone centers are observed over Saudi Arabia, India, and the Western Pacific, while geopotential height is relatively low over eastern BOB (Fig. 2d). A continuous ridgeline is located at $15^{\circ} \mathrm{N}$. The two centers over land can be attributed to strong regional surface sensible heating, whereas the center over the 
Fig. 2 Climatological

ridgelines (thick curve; numbers indicate the isobaric surface) of the subtropical anticyclone at 700,500 , and $200 \mathrm{hPa}$ for a 30 April, b 6 May, and c 14 May. d-f The same as a-c except for streamlines and vorticity (shading, $10^{-5} \mathrm{~s}^{-1}$ ) at $700 \mathrm{hPa}$, with the ridgeline (thick curve) superimposed
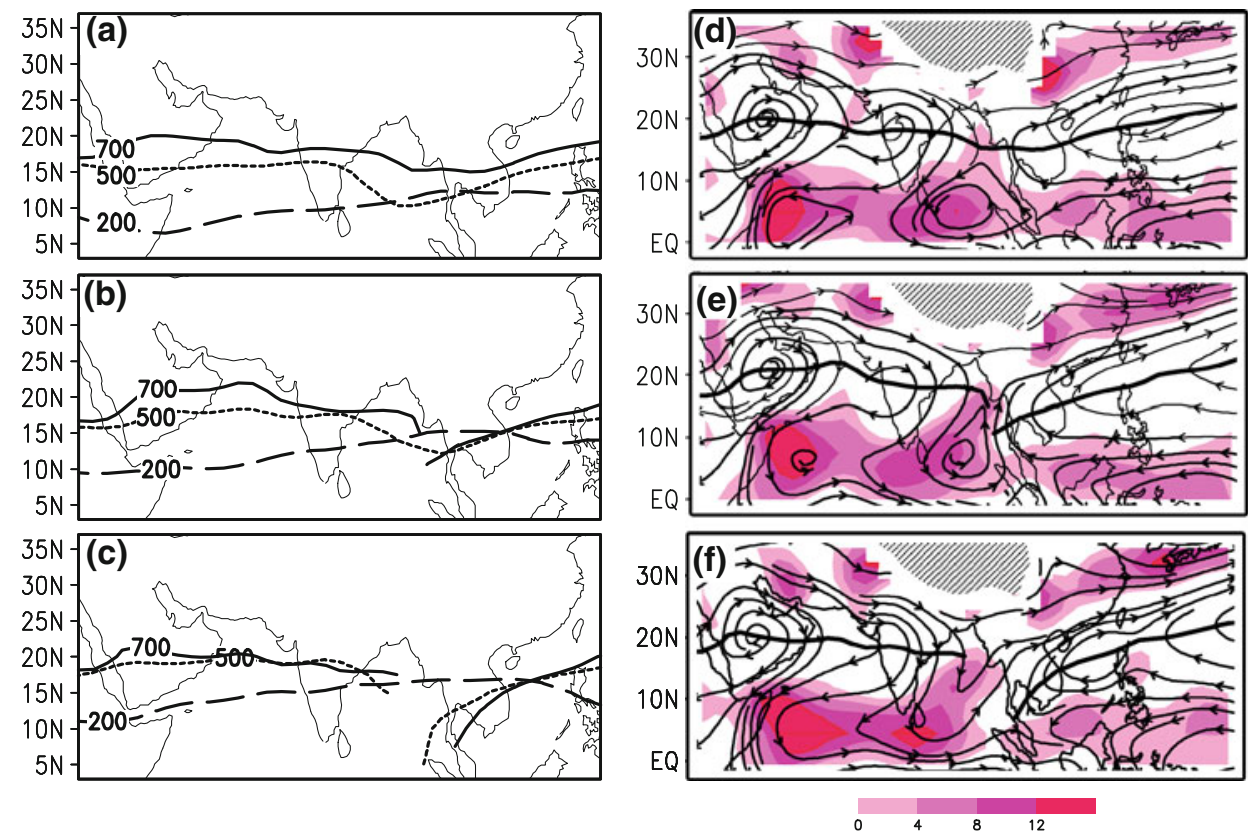

Western Pacific may be due to intensified rainfall over the Indochina Peninsula (Liu et al., 2004). A strong vortex, with vorticity of about $8 \times 10^{-5} \mathrm{~s}^{-1}$, exists over southern BOB. By the time of BOB monsoon onset (Fig. 2e), the $\mathrm{BOB}$ vortex has moved northeastward, the anticyclone over India has weakened, the anticyclone over the Western Pacific has extended southwestward and the western end of its ridgeline has shifted southward from $15^{\circ} \mathrm{N}$ to $10^{\circ} \mathrm{N}$. Consequently, the tropical southwesterly located east of the vortex merges with the subtropical westerly located north of the ridgeline, resulting in breaking of the ridgeline. One week later (Fig. 2f), the BOB vortex has disappeared and the strong southwesterly sweeps over a large area ranging from eastern BOB to the Indochina Peninsula, south China, and the Western Pacific. The earliest Asian summer monsoon onset has arrived in eastern BOB and over the Indochina Peninsula. Therefore, the climate data indicate that development of the BOB vortex plays an important role in leading the Asian summer monsoon onset. Below, we examine a case study with the aim of understanding how the monsoon onset vortex develops over the BOB area.

\section{Oceanic influences on the development of the onset vortex}

\subsection{Evolution of SST with development of the onset vortex}

In 2003, a vortex developed during early May, leading to the BOB monsoon onset. This vortex is choosen for current study because it was formed in the southeastern BOB, took a track first northwestward then northeastward, and had a longer lifetime. Its life cycle is typical of the season. Figure 3 demonstrates the track and intensity evolution in terms of sea surface pressure of the vortex. Its daily location and intensity are determined by searching the low-pressure center at sea-level in the region based on the ERA-40 reanalysis. The resultant track (Fig. 3a) is similar to that provided by JTWC, although not exact. We can therefore diagnose its formation processes, its interaction with the underlying ocean, and its contribution to the Asian summer monsoon onset, focusing on the $\mathrm{BOB}$ area of $80^{\circ}-97^{\circ} \mathrm{E}$ in longitude and $0^{\circ}-20^{\circ} \mathrm{N}$ in latitude.

The BOB monsoon onset in 2003 occurred on May 12, as measured by the monsoon onset index defined by Mao et al. (2002b, 2004). On May 8, before the BOB monsoon onset, a vortex developed over southern BOB and moved northward until May 19 (Fig. 3a). The vortex attained its lowest pressure at sea level on May 13 before weakening and disappearing on May 19 (Fig. 3b). To understand the evolution of the vortex, we recognize three stages: Stage I corresponds to the vortex gestational phase, prior to May 8; Stage II represents the vortex developing phase, from 8 to 13 May; and Stage III corresponds to the vortex decaying phase, from 14 to May 19. Unless otherwise indicated, 5 and 8 May are chosen as being representative of Stage I, while 11 and 14 May are representative of Stages II and III, respectively (see Fig. 3b).

Figure 4 shows the evolution of SST before and after formation of the BOB monsoon vortex. In Stage I, a warm pool $\left(\mathrm{SST}>30.5^{\circ} \mathrm{C}\right)$ occurs in the eastern part of central BOB (Fig. 4a, b), immediately north of the location where the vortex formed. During Stage II, the vortex propagates 
Fig. 3 Evolution of the vortex from 8 to 19 May 2003, showing a the track of the vortex center (identified by sea level pressure), with numbers indicating the date on which the center was at that location, and b the intensity of the vortex, in sea level pressure from ERA-40. The pink curve in a denotes the track produced from the JTWC data

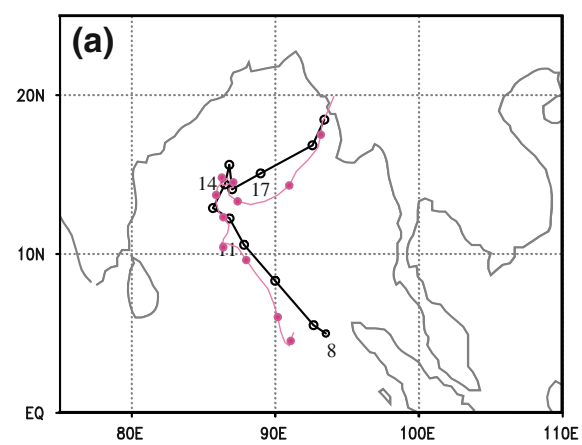

(b)

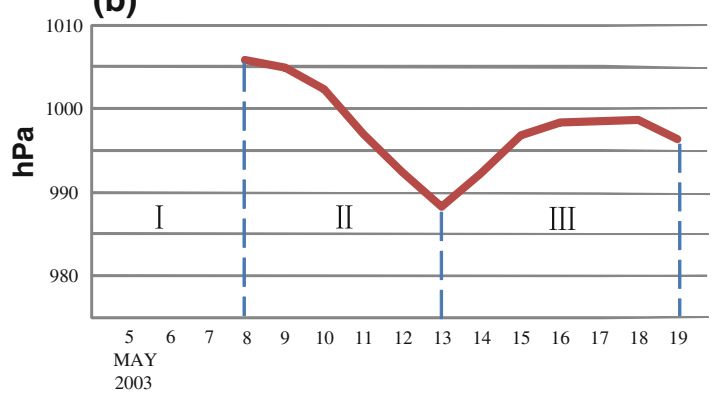

northwestwards toward the warm pool (Fig. 4c) and cold SST is generated behind the vortex in association with precipitation and ocean mixing, as discussed below. During Stage III, after the vortex has matured on May 13 (Fig. 4d), the warm pool decreases in size and the vortex begins to weaken. The vortex track is confined to the area of SST $>30^{\circ} \mathrm{C}$, and the evolution of the vortex is influenced by the warm SST pool.

\subsection{Evolution of sensible heating}

As a boundary condition, SST clearly changed with movement of the vortex in 2003, although it did not directly influence the atmosphere. The air-sea temperature difference determines the occurrence of heating from the sea to the atmosphere, or vice versa. According to the concept of thermal adaption (Wu and Liu 2000), whenever sensible heating occurs from the underlying surface to the atmosphere, cyclonic circulation is generated in the lower layers of the atmosphere.

Figure 5 shows the surface sensible heating (upward is positive) during the three stages of the vortex life cycle. In the northern $\mathrm{BOB}$ area, a common feature is observed throughout the whole period: the ocean heats the atmosphere in eastern BOB but cools the atmosphere in western BOB. This occurs because SST is warmer in the east but colder in the west (Fig. 4) due to local upwelling, as discussed below. Therefore, the eastern part of northern BOB becomes a heat source for the atmosphere, whereas the western part becomes a heat sink. This finding explains why the vortex track, as shown in Fig. 3a, is maintained over eastern BOB.

During the gestational stage on 5 May (Fig. 5a), weak sensible heating appears throughout the entire area of the BOB warm pool. In the southeastern BOB region on 8 May (Fig. 5b), sensible heat is enhanced with a maximum exceeding $15 \mathrm{~W} \mathrm{~m}^{-2}$, centered at $\left(95^{\circ} \mathrm{E}, 5^{\circ} \mathrm{N}\right)$, and the regional surface wind shows cyclonic shear in response to surface forcing induced by this sensible heating. Consequently, the onset vortex is formed in the region. Surface sensible heating around the center of the vortex is intensified during its developing phase. On 11 May (Fig. 5c), the sensible heat flux near the vortex center exceeds $35 \mathrm{~W} \mathrm{~m}^{-2}$, and the surface cyclonic circulation already occupies the entire northern BOB. During the decaying phase, the surface sensible heating associated with the vortex is severely weakened (Fig. 5d); consequently, the onset vortex is weakened. To south of the vortex, as precipitation and ocean mixing result in a rapid decline in SST (Fig. 4d), surface sensible heating becomes negative.

\subsection{Water vapor transport and precipitation over BOB}

The above analysis reveals that the location of the SST warm pool in the eastern Central BOB, along with the remarkable surface sensible heating around the vortex center, plays an important role in the development and evolution of the vortex. It is unclear why this vortex is formed over the southeastern corner of BOB or from where the energy is sourced for its development.

Figure 6 shows the surface vorticity and divergence wind, calculated based on 10-m wind data of the NCEP/ NCAR reanalysis. During the gestational phase (Fig. 6a, b), anticyclonic vorticity dominates the northern BOB area (north of $10^{\circ} \mathrm{N}$ ), while cyclonic vorticity dominates the southeastern area. This pattern is in good correspondence with the distribution of surface wind (Fig. 5a, b): because strong surface wind develops along the equator and over the northwestern coastal ocean region of BOB, the horizontal wind shear must be anticyclonic north of $10^{\circ} \mathrm{N}$, but cyclonic to the south. Therefore, surface air is divergent in the northern $\mathrm{BOB}$ region and convergent in the southeastern region. Accordingly, the southeastern corner of BOB, where the monsoon onset vortex developed on 8 May, is characterized by positive vorticity and wind convergence (Fig. 6b). After the vortex has formed, it is accompanied by remarkable positive vorticity of more than $4 \times 10^{-5} \mathrm{~s}^{-1}$ and strong surface wind convergence from the eastern Arabian Sea, India, and the Southern Hemisphere toward the vortex center (Fig. 6c, d).

The ocean supplies not only surface sensible heat, but also abundant water vapor to the atmosphere, as is evident 
Fig. 4 SST (shading, ${ }^{\circ} \mathrm{C}$ ) from OISST and sea surface wind from NCDC (vectors, $\mathrm{m} \mathrm{s}^{-1}$ ) on a 5 May, b 8 May, c 11 May, and d 14 May 2003. The vortex temporal position is marked by the typhoon symbol
Fig. 5 Daily sensible heat flux from OAFlux (shading, $\mathrm{W} \mathrm{m}^{-2}$ ) and sea surface wind (vectors, $\mathrm{m} \mathrm{s}^{-1}$ ) from NCDC on a 5 May, b 8 May, c 11 May, and d 14 May 2003. The vortex temporal position is marked by the typhoon symbol
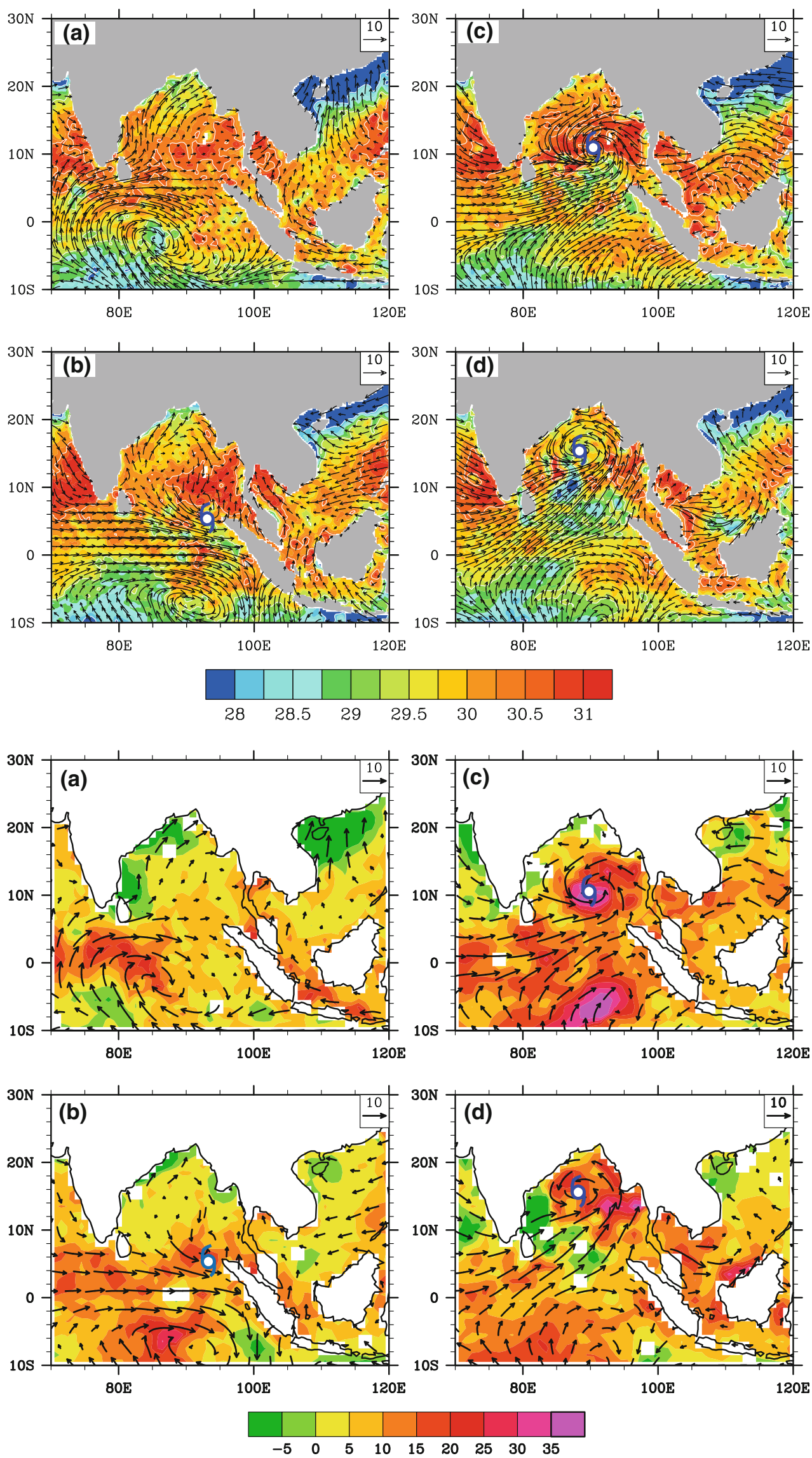
by comparing the surface sensible heat flux (Fig. 5) with the sum of surface sensible and latent heat fluxes (Fig. 11), since surface evaporation is proportional to the surface latent heat flux. Figure 7 shows daily precipitation rate, vertically integrated water vapor flux $\vec{V} q$, and its divergence $\nabla \cdot(\vec{V} q)$. Because

$$
\begin{aligned}
\nabla \cdot(\vec{V} q) & =\nabla \cdot\left(\vec{V}_{\psi} q\right)+\nabla \cdot\left(\vec{V}_{\chi} q\right) \\
& =\nabla \cdot\left(\vec{V}_{\chi} q\right)+\vec{V}_{\psi} \cdot \nabla q,
\end{aligned}
$$

where $\vec{V}_{\psi}$ and $\vec{V}_{\chi}$ are, respectively, the rotational part and divergent part of $\vec{V}$, to illustrate the contribution due to divergent wind, only $\vec{V}_{\chi} q$ (not $\vec{V} q$ ) and its divergence are plotted in Fig. 7. During the gestational phase, water vapor flux is divergent over most of northern BOB but convergent in its southeastern corner, resulting in enhanced precipitation in this latter region (Fig. 7a, b). Latent heat release warms the atmosphere and favors the generation of available potential energy and development of the vortex in the lower atmosphere. During the developing phase, the convergence of water vapor flux in the region surrounding the vortex is greatly intensified and is accompanied by heavy precipitation (Fig. 7c), providing sufficient energy for vortex growth. In the decaying phase (Fig. 7d), the convergence of water vapor flux weakens, resulting in a reduction in the size of the area of intense precipitation over BOB.

\subsection{Energetics and development of the BOB vortex}

Barotropic instability is commonly used to interpret the formation of the monsoon onset vortex in the tropical atmosphere (e.g., Krishnamurti 1981). Because the growth of eddy kinetic energy is proportional to $\left(-\overline{u^{\prime} v^{\prime}} \frac{d \bar{u}}{d y}\right)$, where an over-bar denotes quantities of mean flow and the prime indicates quantities of eddies (as departures from the mean flow), then $\left(-\overline{u^{\prime} v^{\prime}} \frac{d \bar{u}}{d y}>0\right)$ implies the kinetic energy conversion from zonal flow to eddies, favoring vortex development. However, the barotropic kinetic energy conversion from zonal mean to eddy is negligible during the gestational phase of the vortex examined in the present case study (not shown). In fact, our analysis reveals that the baroclinic instability associated with the conversion from available potential energy to kinetic energy contributes to the triggering of vortex formation.

Figure $8 \mathrm{a}, \mathrm{b}$ shows the distribution of $(-\omega T)$ on 7 and 8 May, respectively, at the time of vortex formation. $-\omega T$ is generally negative over northern BOB, but positive over the south. This finding indicates that over northern BOB, where surface anticyclonic circulation is dominant, the total energy conversion is from kinetic to available potential; in contrast, over southern $\mathrm{BOB}$, where surface cyclonic circulation prevails, the conversion is from available potential energy to kinetic energy. Over the southeastern corner of BOB on 8 May, the positive value of $-\omega T$ (i.e., the growth rate of kinetic energy) increases and
Fig. 6 Relative vorticity (shading, $10^{-5} \mathrm{~s}^{-1}$ ) and divergent wind (vectors) at $10 \mathrm{~m}$ above sea level from NCEP-1 on a 5 May, b 8 May, c 11 May, and d 14 May 2003. The vortex temporal position is marked by the typhoon symbol
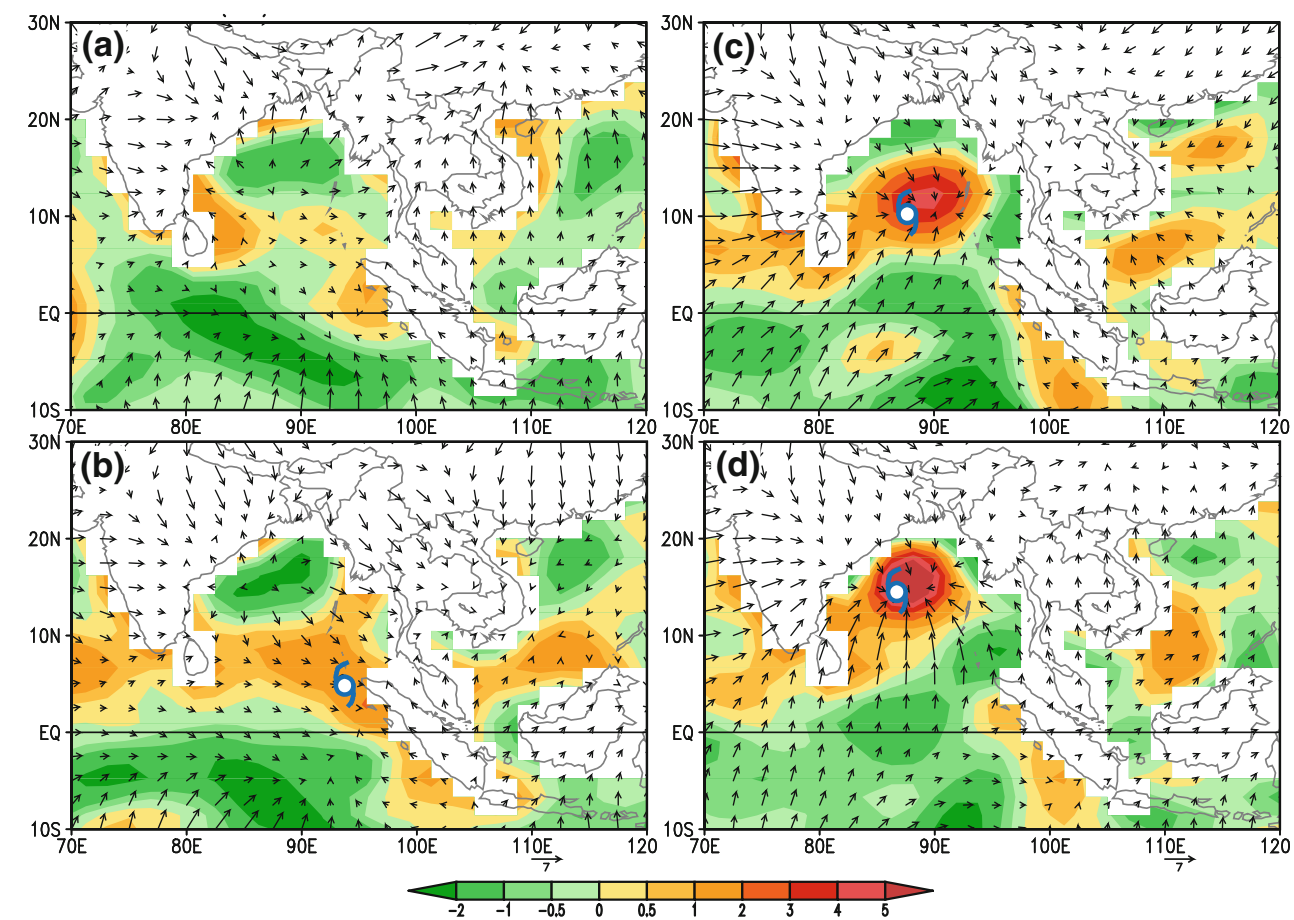
Fig. 7 Precipitation (shading, $\mathrm{mm}$ day $^{-1}$ ), vertically integrated water vapor transport $\vec{v}_{\mathrm{X}} q$ (vectors, $\mathrm{kg} \mathrm{m}^{-1} \mathrm{~s}^{-1}$ ) due to divergent wind, and water vapor transport divergence

$\nabla \cdot\left(\vec{v}_{\mathrm{X}} q\right)$ (contours,

$\left.10^{-4} \mathrm{~kg} \mathrm{~m}^{-2} \mathrm{~s}^{-1}\right)$ from

NCEP-1 on a 5 May, b 8 May,

c 11 May, and d 14 May 2003.

The dashed line indicates divergence and the solid line indicates convergence. The position of the vortex center is marked by a red typhoon symbol. The contour interval is 0.5 in the case that the absolute value of divergence is less than $1 \times 10^{-4} \mathrm{~kg} \mathrm{~m}^{-2} \mathrm{~s}^{-1}$

(otherwise 1.0)
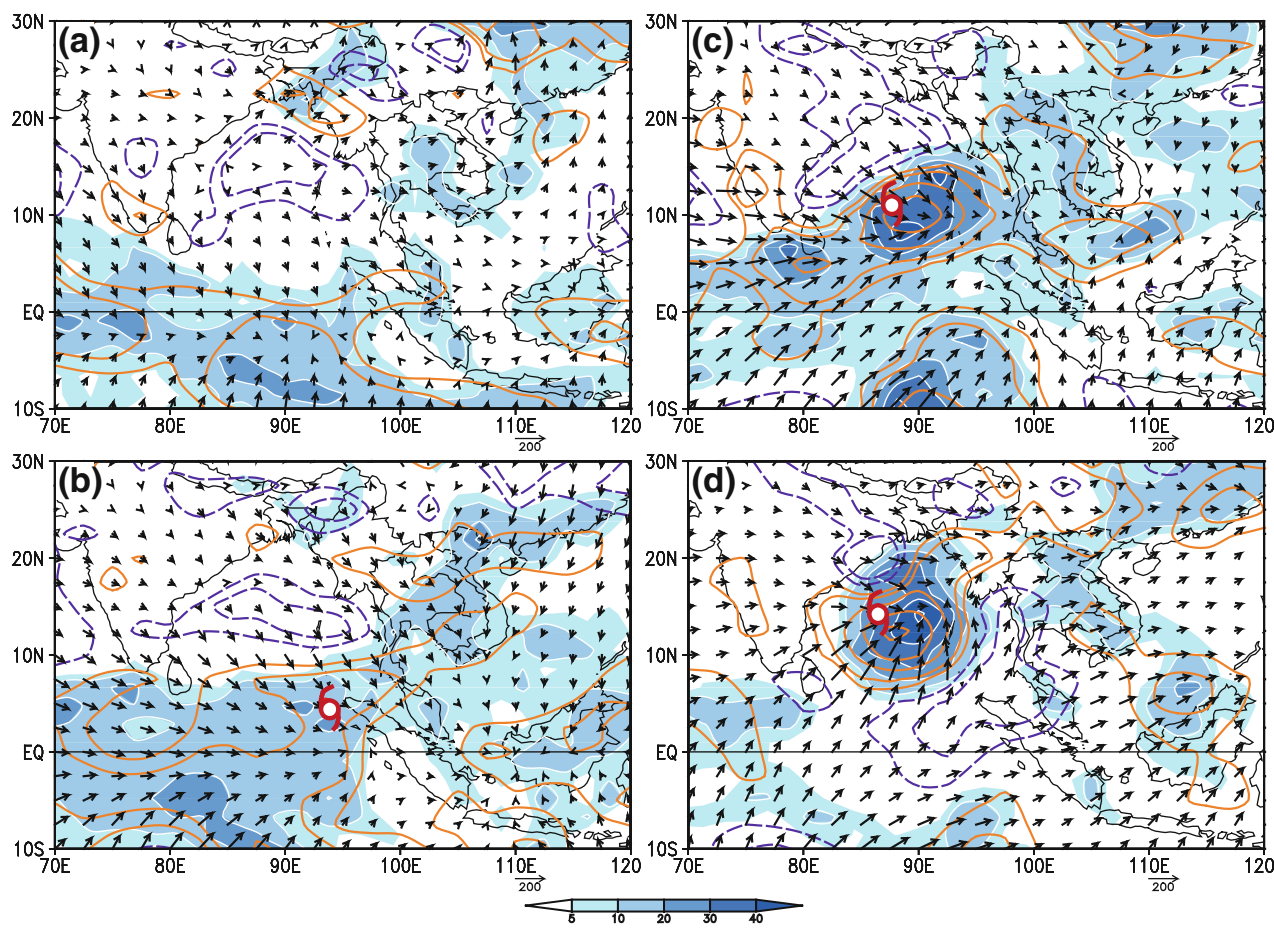

reaches $10 \mathrm{~Pa} \mathrm{~K} \mathrm{~s}^{-1}$ at the time of vortex formation in the region.

During the gestational phase, the surface air temperature $T$ and SST in the region are warm (Fig. $4 \mathrm{a}, \mathrm{b}$ ), and surface sensible heating $Q$ is enhanced ( $>15 \mathrm{~W} \mathrm{~m}^{-2}$; Fig. $\left.5 \mathrm{~b}\right)$; consequently, available potential energy is generated $(Q T>0)$ and stored in the region. In the case that the irrotational flow brings water vapor into the region from northern $\mathrm{BOB}$, the Arabian Sea, and the Southern Hemisphere (Figs. 6a, b, 7a, b), the air rises and becomes warmer due to the latent heat release associated with rainfall, leading to $-\omega T>0$. The stored available potential energy is then released to enhance the kinetic energy, triggering vortex formation. Nevertheless, barotropic instability still plays an important role during the developing and decaying phases of the vortex. The large positive value of $\left(-\overline{u^{\prime} v^{\prime}} \frac{d \bar{u}}{d y}\right)$ in the region east of the vortex on 11 and 14 May (Fig. 8c, d, respectively, the zonal mean is averaged over $60^{\circ}-120^{\circ} \mathrm{E}$ ) indicates that during these phases, zonal kinetic energy in the vortex domain is converted to eddy kinetic energy over the area east of the vortex, and the vortex develops and moves eastward.

\section{Influence of the atmosphere and ocean mixing on SST evolution in BOB}

\subsection{Formation of the BOB SST warm pool in spring}

An analysis of weekly OISST data demonstrates that in 2003 over the BOB area, SST increased gradually from below $27.5^{\circ} \mathrm{C}$ in mid-January to a maximum of $30.3^{\circ} \mathrm{C}$ in early May, then decreaded sharply afterwards (Fig. 9a). The spatial distribution of SST increase from the week centered on 6 April to the week centered on 27 April (herein referred to as Week 6 April and Week 27 April, respectively) reveals that about 1 month before vortex formation, SST in the Indian Ocean became cooler south of the equator and became warmer north of the equator, over most areas (Fig. 9b). Over the Arabian Sea and South China Sea, SST warming was greater in the west; whereas over BOB, warming was greater in the east, with remarkable cooling in the northwest and southwest. SST was cold over the northwestern Arabian Sea and SCS in early April (Fig. 9c); consequently, a warm pool $\left(\mathrm{SST}>30.75^{\circ} \mathrm{C}\right.$ ) formed in the central and eastern BOB by the end of April (Fig. 9d).

In the tropics, SST and ocean motion are strongly influenced by surface wind. Figure 4 shows the evolution of surface wind, in addition to SST. During the gestational stage, two strong surface-wind belts developed in the BOB area (Fig. 4a and 4b). South of BOB, a near-equator cyclone centered at $\left(85^{\circ} \mathrm{E}, 5^{\circ} \mathrm{S}\right)$ developed in the Southern Hemisphere (Fig. 4a), associated with a strong crossequator flow from the Southern Hemisphere between $70^{\circ}$ and $80^{\circ} \mathrm{E}$, which was accompanied in turn by the development of a near-equator westerly immediately south of Sri Lanka. As the cyclone propagated eastward, the westerly belt intensified and extended eastward to approach Java Island by 8 May (Fig. 4b). Another strong wind belt is observed over the western coastal ocean of BOB. This belt 
Fig. 8 Distribution at $850 \mathrm{hPa}$ of $-\omega T\left(\mathrm{~Pa} \mathrm{~K} \mathrm{~s}^{-1}\right)$ on a 7 May and $\mathbf{b} 8$ May 2003, and distribution of $-\overline{u^{\prime} v^{\prime}} \frac{d \bar{u}}{d y}\left(\mathrm{~m}^{2} \mathrm{~s}^{-3}\right)$ from NCEP-1 on c 11 May and d 14 May 2003. The position of the vortex center is marked by a black typhoon symbol
Fig. 9 a Time series of areaaveraged weekly SST $\left({ }^{\circ} \mathrm{C}\right)$ from OISST over the BOB area $\left(80-97^{\circ} \mathrm{E}, 0-20^{\circ} \mathrm{N}\right)$. b SST increase from the Week 6 April to the Week 27 April. c Weekly SST distribution for Week 6 April. d As in c, except for Week 27 April
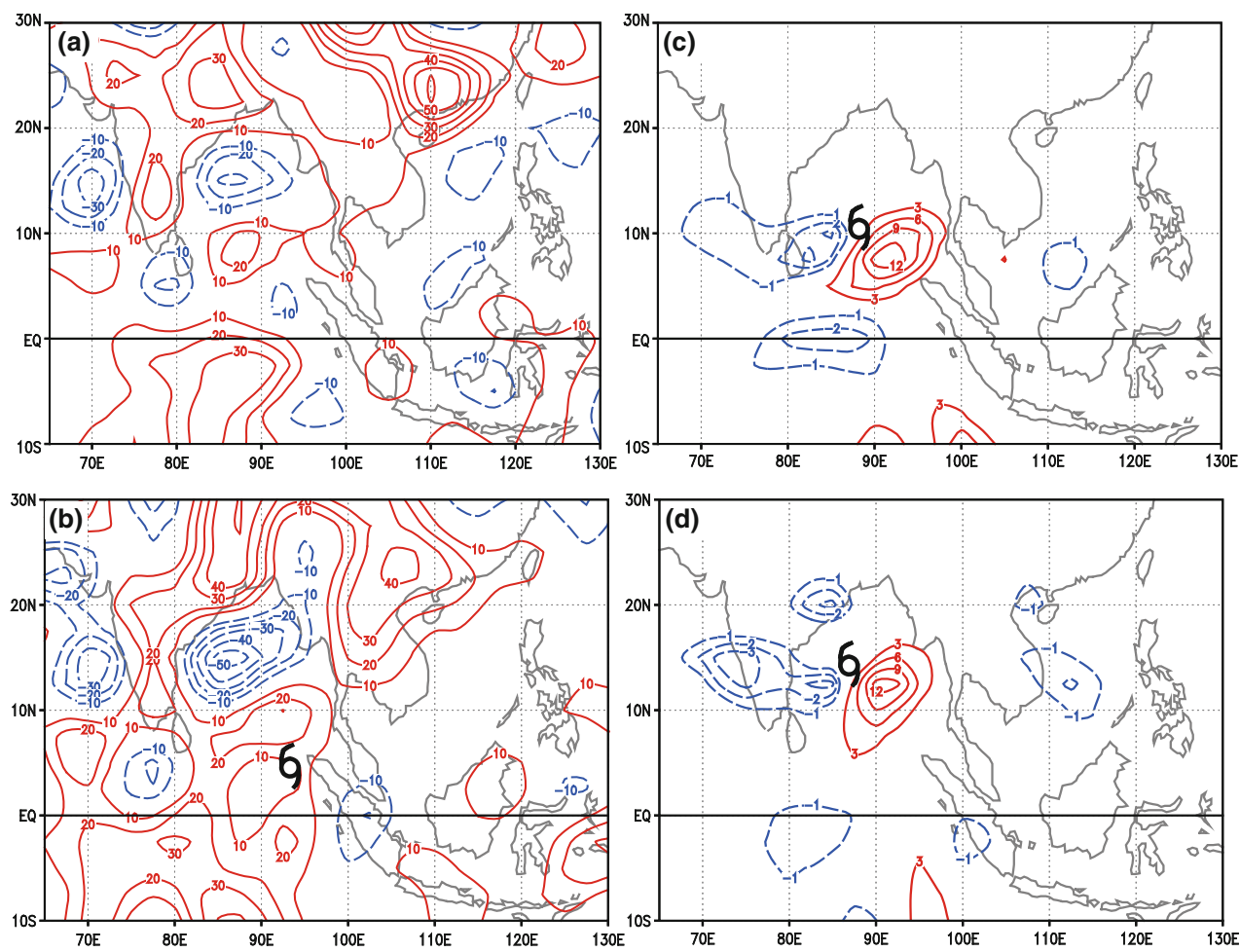
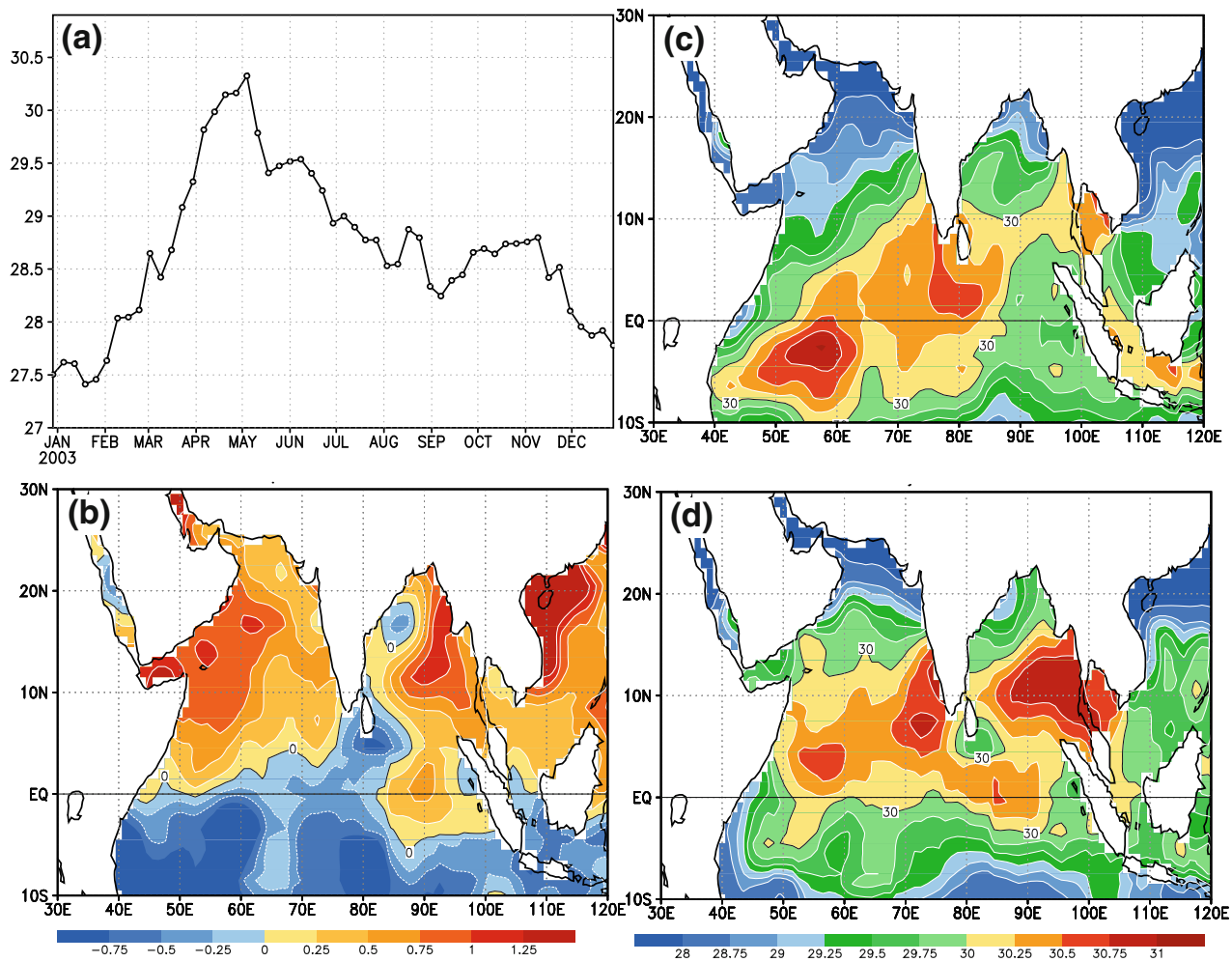

induced a pronounced surface anticyclone over northern BOB (Fig. 4a, b) that provided clear sky and sunny conditions in the atmosphere, driving a convergent surface ocean current in the area with down-welling (Sect. 5.2 or
Fig. 12). These two strong wind belts occurred either side of the northern $\mathrm{BOB}$; while in the central and eastern parts of BOB the surface winds were weak, where the warm pool formed. During the developing phase, the warm pool 
remained north of the vortex (Fig. 4c), whereas during its decaying phase the warm pool was weakened due to the intensification of surface wind and precipitation (Fig. 4d).

The appearance of the BOB warm pool in spring is at least partly attributed to the weak local surface wind, because SST is determined externally by the net surface heat flux and because the sea-surface sensible heat flux and latent heat flux are affected by surface wind. At the sea surface, the net heat flux $Q_{N}$, which is determined by the surface net downward radiation $Q_{R}$, and upward latent heat release $Q_{L}$ and sensible heat release $Q_{S}$, can be expressed as

$Q_{N}=Q_{R}-\left(Q_{L}+Q_{S}\right)$

In general, $Q_{R}$ is a heat source for the sea and $\left(Q_{L}+Q_{S}\right)$ is a dissipation sink. The net radiation $Q_{R}$ is determined by the full-sky downward shortwave radiation subtracted from the upward longwave radiation at the surface.

Over the central and northern $\mathrm{BOB}, Q_{R}$ was strongly positive $\left(>220 \mathrm{~W} \mathrm{~m}^{-2}\right)$ during the gestational phase (Fig. 10a), supplying plentiful heat to the sea over almost the entire BOB area, resulting in enhanced SST. Consequently, SST across most of BOB was warmer than that in other areas (see Fig. 4a, b). With formation of the monsoon onset vortex on 8 May (Fig. 10b), cloud and convection developed around the vortex, and $Q_{R}$ in the region became weaker $\left(<80 \mathrm{~W} \mathrm{~m}^{-2}\right)$. During the developing and decaying phases of the vortex, convection and precipitation were further intensified in the region surrounding the monsoon onset vortex; consequently, $Q_{R}$ became negative (Fig. 10c, d) and SST became cooler (Fig. 4c, d).

Figure 11 shows the sum of upward latent heat flux and sensible heat flux $\left(Q_{L}+Q_{S}\right)$. Compared with Fig. 5, $Q_{S}$ is much smaller than $\left(Q_{L}+Q_{S}\right)$ in Fig. 11, and the release of latent heat flux prevails over the surface sensible heat flux in terms of cooling the ocean. During the gestational phase, $\left(Q_{L}+Q_{S}\right)$ was very large near the equator, immediately beneath the strong equatorial surface westerly, but was relatively small in the eastern part of central BOB (Fig. 11a, b), where the surface wind was weak.

Taken together, Figs. 11a and 10a reveal that prior to formation of the Asian monsoon onset vortex, the eastern part of central BOB experienced relatively little heat loss because of the weak surface wind and strong insolation because of the clearer sky under the controlling surface anticyclonic circulation. As shown in Fig. 12, the ocean mixed layer depth in the northern BOB is only $10-20 \mathrm{~m}$ in the gestational period. Strong solar radiation (Fig. 10) together with weak energy loss (Fig. 11) act onto a very thin $(10-20 \mathrm{~m})$ mixed layer (Fig. 12), the SST in this region presents a much more rapid increase than that in other parts of BOB (Fig. 9b). Consequently, a BOB warm pool formed in the region during early spring (Figs. 4a, 9d). Note that the controlling surface anticyclonic circulation over northern BOB was related to strong southwesterly forcing over the northwestern coastal ocean; therefore, we can attribute the formation of the spring $\mathrm{BOB}$ warm pool to the heterogeneous nature of surface wind forcing over the BOB area. During the developing and decaying phases, as strong cyclonic circulation developed over the entire $\mathrm{BOB}$ and moved northward, a strong surface southwesterly sweeps over most of BOB (Fig. 11c, d) and $\left(Q_{L}+Q_{S}\right)$ increases northward, with a center exceeding $300 \mathrm{~W} \mathrm{~m}^{-2}$. SST over BOB decreases and the BOB warm pool shrinks to the area within the Bay of Siam (Fig. 4d).

\subsection{Influence of vertical mixing on SST}

SST (equivalent to mixed-layer temperature, MLT) in the tropical ocean is known to be determined by the net heat budget $Q$ of the mixed layer, which in turn is primarily governed by the net surface heat fluxes $Q_{N}$, the lateral advection of heat $Q_{V}$, and vertical mixing $Q_{e}$. $Q_{e}$ measures the entrainment of heat across the bottom of the mixed layer (McPhaden and Hayes 1991); i.e.,

$Q=Q_{N}-Q_{v}-Q_{e}$,

where

$Q_{v}=\rho_{0} C_{p} h \mathbf{V} \cdot \nabla T$

and

$Q_{e}=\rho_{0} C_{p} h W_{e} \Delta T_{h} / h$,

where $V$ is the horizontal current velocity; $\nabla T$ is the horizontal temperature gradient in the mixed layer; $W_{e}$ is the entrainment velocity at the base of the mixed layer; $\Delta T_{h}$ is the temperature drop below the mixed layer, which is calculated as the difference between the temperature at the mixed-layer depth (MLD) and at $5 \mathrm{~m}$ below the MLD; $\rho_{0}$ is the density of sea water; $C_{p}$ is the specific heat of sea water; and $h$ is MLD. In the current study, NCEP GODAS pentad data (e.g., $\boldsymbol{V}, W_{e}$, and temperature profile) are used to calculate the terms in the above equations. Since the vertical velocity $W_{e}$ was obtained based on the horizontal divergence/convergence of the Ekman transport (Gill 1982), it represents an entrainment rate from below at the base of the mixed layer.

Before evaluating the net heat budget in the mixed layer, we diagnosed the evolution of the mixed layer depth in 2003, averaged over the BOB area. The evolution (figure not shown) is similar to that of SST shown in Fig. 9a. The MLD remains as deep as $50 \mathrm{~m}$ in the winter months under the wintertime northeasterly monsoon circulation. From mid-March, as the winter monsoon ceases, the MLD gradually becomes thinner and attains a minimum of $30 \mathrm{~m}$ by the end of April. As the BOB vortex develops in early 
Fig. 10 Net surface radiation flux $\left(\mathrm{W} \mathrm{m}^{-2}\right.$, downward fullsky shortwave radiation minus upward longwave radiation, with downward being positive) derived from OAFlux data on a 5 May, b 8 May, c 11 May, and d 14 May 2003. Thick black curve denotes the vortex track, with its position marked by the typhoon symbol
Fig. 11 Surface upward latent heat flux plus sensible heat flux from OAFlux (shading, with upward positive; $\left.\mathrm{W} \mathrm{m}^{-2}\right)$, and sea surface wind (vectors, $\mathrm{m} \mathrm{s}^{-1}$ ) on a 5 May, b 8 May, c 11 May, and d 14 May 2003. The vortex position is marked by the typhoon symbol
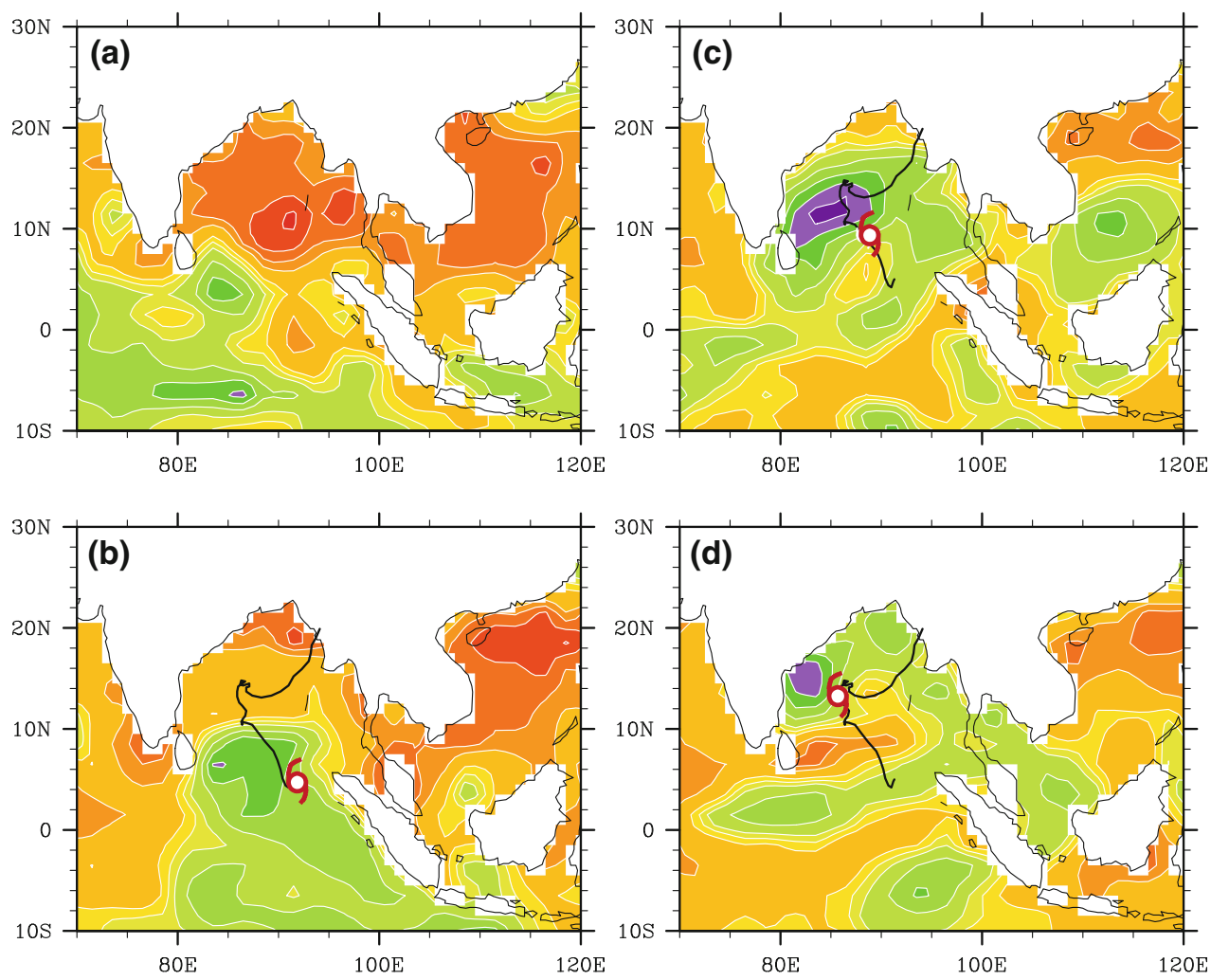

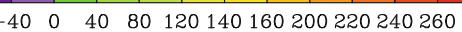
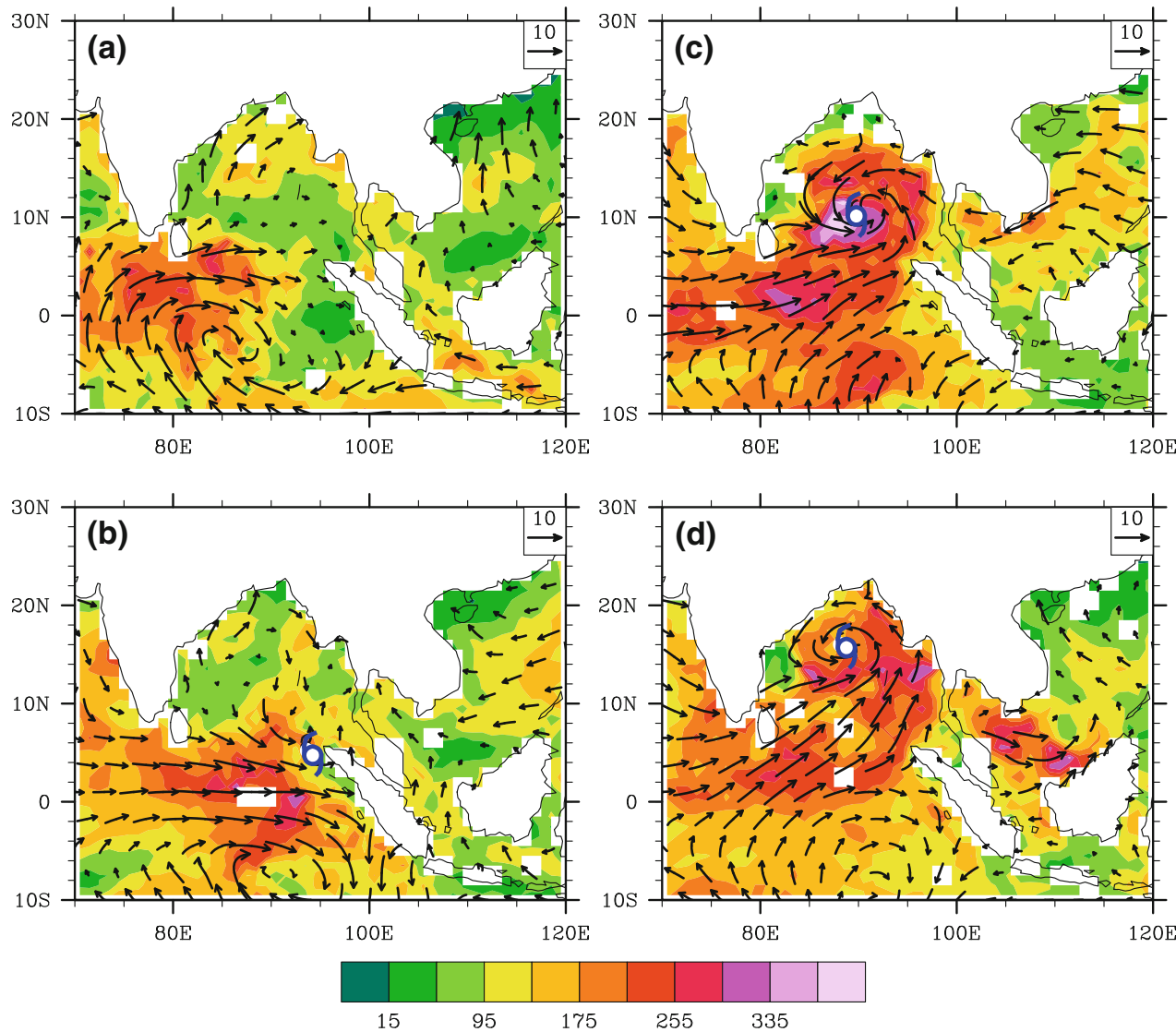
Fig. 12 Mixed-layer depth (unit: $\mathrm{m}$ ) from GODAS in a the second pentad and $\mathbf{b}$ the third pentad of May 2003. c, d As in a, b except for vertical mixing heat flux $Q_{e}\left(\mathrm{~W} \mathrm{~m}^{-2}\right)$ across the bottom of the mixed-layer and sea current at $5 \mathrm{~m}$ depth in the ocean (vectors). Thick black curve denotes the vortex track, with white segments indicating the track during the pentad of interest
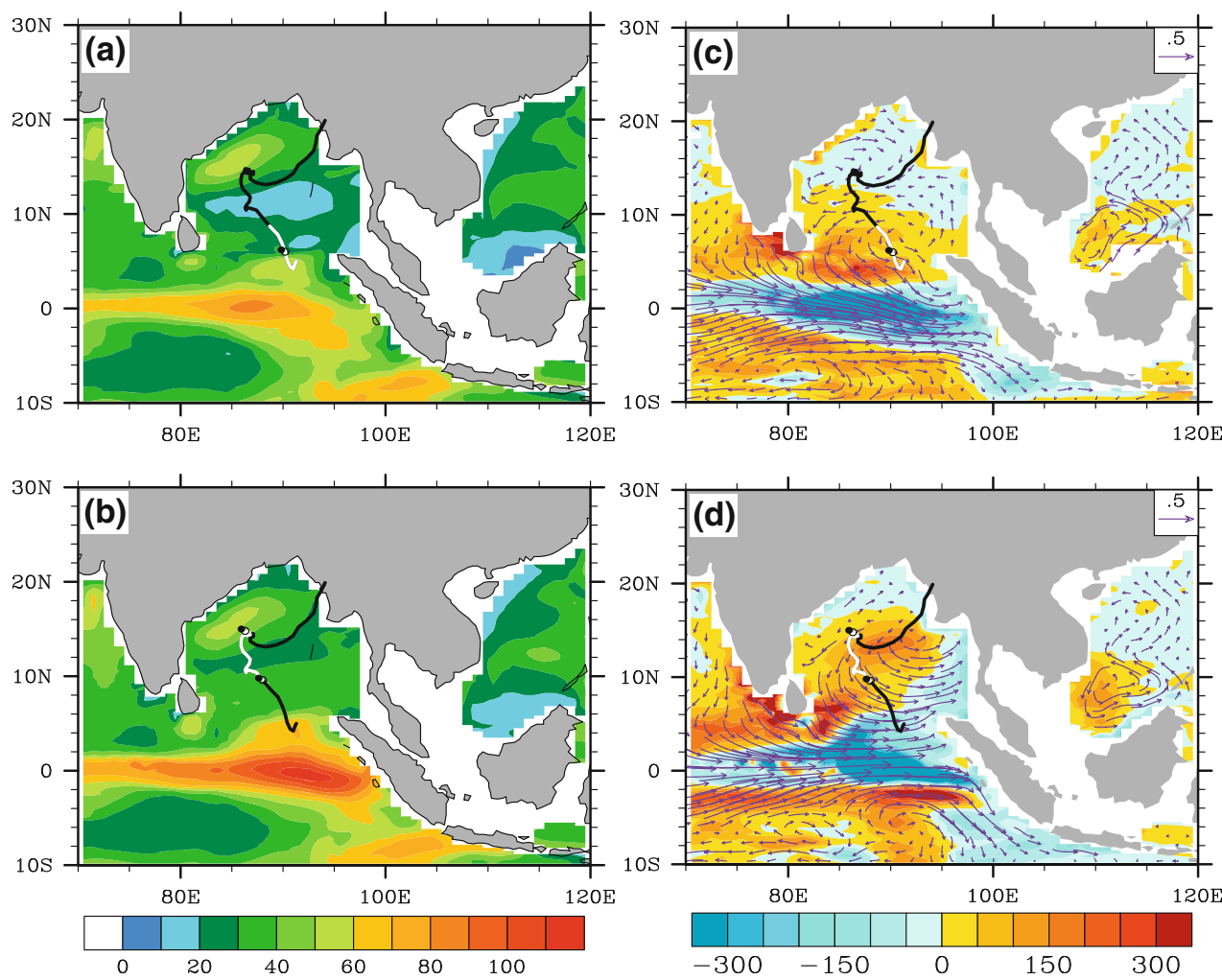

May and with the ensuing onset of the Asian summer monsoon, MLD in BOB shows a marked deepening. Because the monsoon onset vortex develops during 8-19 May, the second and third pentads in May are chosen for analysis to illustrate the spatial distribution of the MLD during the gestational and developing/decaying phases of the vortex.

During the gestational phase, the MLD is less than $20 \mathrm{~m}$ over the Central BOB in the area ahead of the trajectory of the vortex (Fig. 12a). In the third pentad of May (May 11-15), during the developing and decaying phases of the vortex, the depth of the mixed layer increases, exceeding $50 \mathrm{~m}$ near the vortex center by 15 May (Fig. 12b). This finding indicates that during early May, MLD is small. When the BOB vortex develops, the surface wind is so strong that the local vertical mixing is expected to be important in influencing the net heat budget of the mixed layer and SST.

In the net heat budget equation, $Q_{V}$ is an order of magnitude smaller than $Q_{e}$ or $Q_{N}$ in the tropics (data not shown), meaning that it can be ignored. The characteristics of $Q_{N}$ and its evolution during the life cycle of the BOB vortex have been described in previous sections (Figs. 10, 11). Here, we seek to assess the importance of vertical mixing in governing the evolution of SST. In fact, vertical mixing $Q_{e}$ represents the upward Ekman pumping forced by sea surface wind.
Figures $12 \mathrm{c}$ and $12 \mathrm{~d}$ demonstrate that strong downwelling occurs along the equator and to the south of the maximum axis of the surface westerly. Downwelling also appears in northern $\mathrm{BOB}$, where a surface anticyclone occurs. Strong upwelling occurs in southern BOB, particularly north of the maximum axis of the surface westerly. Upwelling also appears offshore from India, associated with an offshore current related to the development of a strong local surface southwesterly east of the surface cyclonic circulation that occurs over India. During the second pentad of May, the sea surface wind is weak over most of northern BOB; consequently, $Q_{e}$ (Fig. 12c) is small in this region $\left(<50 \mathrm{~W} \mathrm{~m}^{-2}\right)$ during the gestational stage of the vortex. It is much weaker than the net surface radiation $Q_{R} \quad\left(>240 \mathrm{~W} \mathrm{~m}^{-2}\right.$; Fig. 10a, b) or net surface flux (55-135 $\mathrm{W} \mathrm{m}^{-2}$; Fig. 11a, b).

In the third pentad of May (11-15 May), the vortex intensifies over northern $\mathrm{BOB}$, where the pre-existing downwelling is replaced by strong upwelling, MLD near the vortex center becomes deeper (exceeding $50 \mathrm{~m}$ by 15 May; Fig. 12b), and $Q_{e}$ around the track of the vortex over northern $\mathrm{BOB}$ exceeds $150 \mathrm{~W} \mathrm{~m}^{-2}$ (Fig. 12d), which is comparable with or even stronger than the net surface radiation $Q_{R}\left(<100 \mathrm{~W} \mathrm{~m}^{-2}\right.$; Fig. 10c, d). Because the mixed layer remains shallow in front of the vortex track, and because mixing induced by the vortex is strong when the vortex arrives, the cold, deep ocean water is stirred into 
the mixed layer. This mixing process, together with the strong surface latent and sensible flux release ( $>150 \mathrm{~W} \mathrm{~m}^{-2}$; Fig. $\left.11 \mathrm{c}, \mathrm{d}\right)$, contributes to a rapid decrease in SST (Fig. 4d) along the passage of the vortex, and to the decay of the vortex.

\section{External modulation of air-sea interaction over BOB and Asian monsoon onset}

The above analyses reveal the critical importance of the surface wind distribution in modulating air-sea interaction in $\mathrm{BOB}$ and in generating the spring $\mathrm{BOB}$ warm pool and the BOB onset vortex of the Asian summer monsoon. Therefore, it is necessary to investigate the origin of this surface wind pattern.

Figure 13a, $\mathrm{b}$ shows the evolution from 1 March to 30 June of the surface latent heat flux and surface sensible heat flux, respectively, averaged between $10^{\circ}$ and $20^{\circ} \mathrm{N}$ across the Arabian Sea, Indian Subcontinent, BOB, Indochina Peninsula, and the SCS. In the spring, prior to formation of the BOB vortex, despite the occurrence of mild variations over the ocean, there exists a remarkable difference in surface thermal features between the Indian Subcontinent and the Indochina Peninsula. At this time, the Indian Subcontinent is experiencing the dry season, when surface evaporation is weak and the surface sensible heat flux exceeds $120 \mathrm{~W} \mathrm{~m}^{-2}$. In contrast, the climate of the Indochina Peninsula at this time is warm and moist, where the surface latent heat flux exceeds $125 \mathrm{~W} \mathrm{~m}^{-2}$ and surface sensible heating is generally less than $90 \mathrm{~W} \mathrm{~m}^{-2}$. By 8 May, at which time the monsoon vortex is formed, the averaged sensible heat flux over the Indochina Peninsula is already less than $30 \mathrm{~W} \mathrm{~m}^{-2}$.

This thermal contrast is seen more clearly from the spatial distributions of surface latent heat flux and wind at $850 \mathrm{hPa}$ on 8 May (Fig. 13c). Evaporation is weak over the dry surface of India, whereas it is stronger over the wet Indochina Peninsula, where rainfall is abundant (Fig. 7b). Of note, the prevailing wind at $850 \mathrm{hPa}$ is northwesterly over India but southerly over the Indochina Peninsula. According to Wu et al. (2007) and Wang et al. (2008), this pattern of prevailing wind is typical of the season because mechanical and thermal forcing of the Tibetan Plateau generates a flow dipole with anticyclonic circulation to the north and cyclonic circulation to the south. The prevailing northerly over India brings cold and dry air from the north, thereby intensifying the land-air temperature difference, leading in turn to strong surface sensible heat release (see Fig. 13d, which shows the distributions of surface sensible heat flux and 10-m wind on 8 May). Over most of India, surface sensible heating exceeds $150 \mathrm{~W} \mathrm{~m}^{-2}$. Because the sensible heating $Q$ over India decreases with increasing height, negative vorticity is generated in the lower troposphere (Wu and Liu 2000). In the absence of zonal vorticity advection and following the Sverdrup vorticity balance, we have

$\beta v=(f+\zeta) \theta_{z}^{-1} \frac{\partial Q}{\partial z}, \quad \theta_{z} \neq 0$,

indicating that positive planetary vorticity should be transferred from the north to maintain the local vorticity balance, thus leading to the development of a northerly in return. As this process continues, the surface sensible heating and generation of negative vorticity form a positive feedback loop via the development of the northerly wind, and intense surface sensible heat flux is maintained, similar to the mechanism involved in the formation of desert areas (see Wu et al. 2009). According to the atmospheric thermal adaptation theory (Hoskins 1991; Wu and Liu 2000), remarkable surface cyclonic circulation must form in response to such strong surface thermal forcing. Consequently, a strong surface northwesterly forms along the west coast of India and a southwesterly forms along the east coast (Fig. 13d).

The development of a strong southwesterly over northwestern $\mathrm{BOB}$, combined with the development of the nearequator westerly over southern $\mathrm{BOB}$, induces a surface anticyclone in northern BOB and a cyclone in the south. This pattern of surface circulation remains over BOB at $850 \mathrm{hPa}$ (Fig. 13c), and is even discernable at $700 \mathrm{hPa}$ prior to formation of the monsoon vortex (Fig. 14a, b). However, unlike in the lower layers, anticyclonic circulation over northern $\mathrm{BOB}$ at $700 \mathrm{hPa}$ occurs as part of a continuous "ridgeline" of the subtropical anticyclone belt (thick line along $18^{\circ}-20^{\circ} \mathrm{N}$ in Fig. 14b). A zonal belt of easterlies prevails to the south of the ridgeline, whereas a zonal westerly prevails to the north, representing a typical pattern of the wintertime circulation. After the BOB vortex has formed on 8 May, as the vortex develops and moves northward, part of the ridgeline west of $95^{\circ} \mathrm{E}$ is also shifted northwards to about $20^{\circ} \mathrm{N}$ (Fig. 14c). With further development and northward movement of the vortex, the originally continuous easterly belt in the tropics is strongly interrupted: the southerly and southwesterly over the eastern portion of the vortex merge with the westerly at higher latitudes, the ridgeline splits over eastern BOB and western Indochina Peninsula in the longitude domain between $93^{\circ}$ and $105^{\circ} \mathrm{E}$ on 12 May (data not shown), and the Asian summer monsoon commences.

Before the monsoon onset (Fig. 14c), all the ridgelines tilt southward from the lower to higher troposphere, corresponding to the general winter feature of warm in the south and cold in the north. After the monsoon onset (Fig. 14d), the ridgelines at 850 and $700 \mathrm{hPa}$ show strong northward movement in the longitude domain west of 
Fig. 13 Time-longitude crosssections (averaged between $10^{\circ}$ and $20^{\circ} \mathrm{N}$ ) of a surface latent heat flux and $\mathbf{b}$ surface sensible heat flux from March to June, 2003. c surface latent heat flux (shading) and 850-hPa wind (vectors), and $\mathbf{d}$ surface sensible heat flux (shading) and 10-m surface wind (vectors) on 8 May 2003 from NCEP-1. Units are $\mathrm{W} \mathrm{m}{ }^{-2}$ for flux and $\mathrm{m} \mathrm{s}^{-1}$ for wind. The two horizontal lines in $\mathbf{a}$ and $\mathbf{b}$ denote, respectively, the times of the genesis and disappearing of the monsoon onset vortex
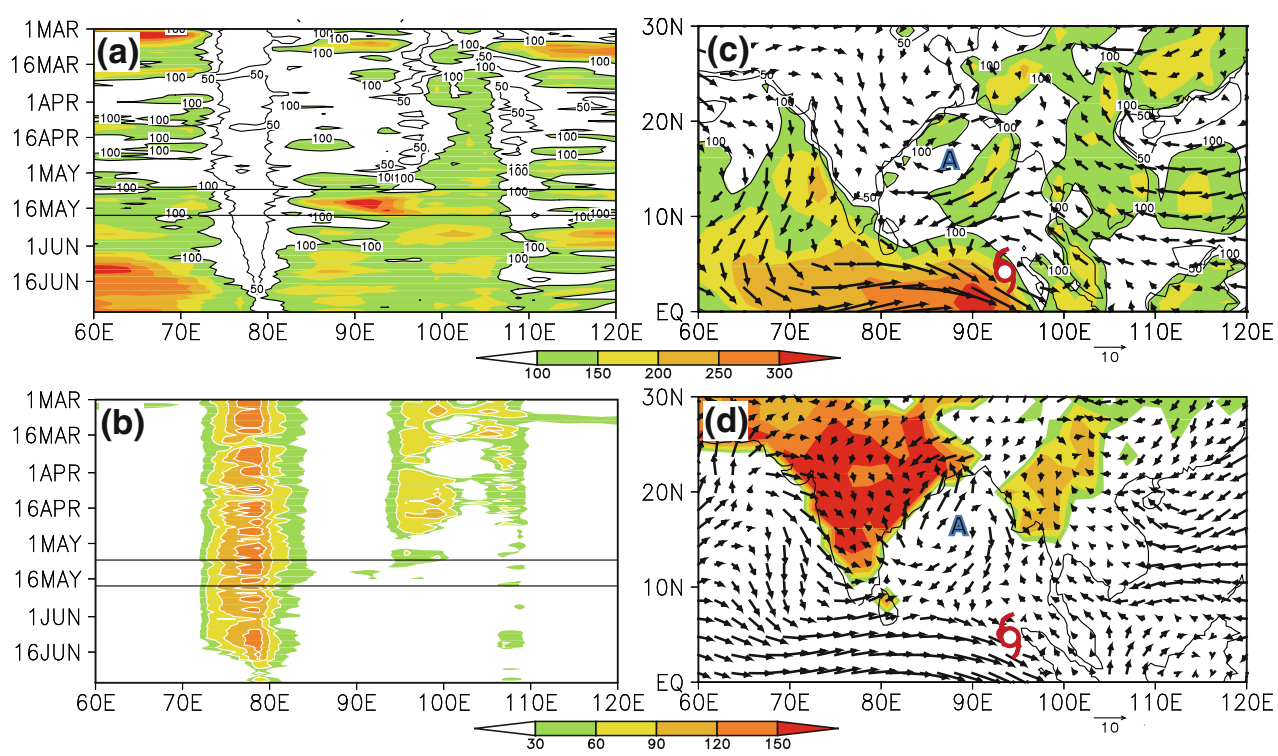

$93^{\circ} \mathrm{E}$, but show southward movement in the longitude domain east of $105^{\circ} \mathrm{E}$. Consequently, the ridgelines between $93^{\circ} \mathrm{E}$ and $105^{\circ} \mathrm{E}$ are broken in the lower troposphere, and warm and moist air is transported from eastern BOB to the southeastern Tibetan Plateau and southern China. By May 14th, although the ridgelines still tilt southward with increasing height west of $93^{\circ} \mathrm{E}$ and east of $110^{\circ} \mathrm{E}$, they tilt northward in the region between $93^{\circ} \mathrm{E}$ and $105^{\circ} \mathrm{E}$, indicating the establishment of the general summer feature of warm air in the north and cold air in the south. It is evident that the development of the BOB vortex in 2003 played an important role in leading the earliest Asian summer monsoon onset and the seasonal transition from winter to summer in eastern BOB and over the western Indochina Peninsula.

\section{Summary and discussion}

In 2003, the monsoon onset vortex formed over the southeastern corner of BOB on 8 May before propagating northward and northeastward, attaining maximum intensity
Fig. 14 Streamline and ridgeline (thick curve) of the subtropical high at $700 \mathrm{hPa}$ from NCEP-1 on a 5 May, b 8 May, c 11 May, and d 14 May 2003. In $\mathbf{c}$ and $\mathbf{d}$, the ridgelines at five isobaric surfaces (850, $700,500,300$, and $200 \mathrm{hPa}$ ) are shown with different colors and are marked by $8,7,5,3$, and 2 , respectively
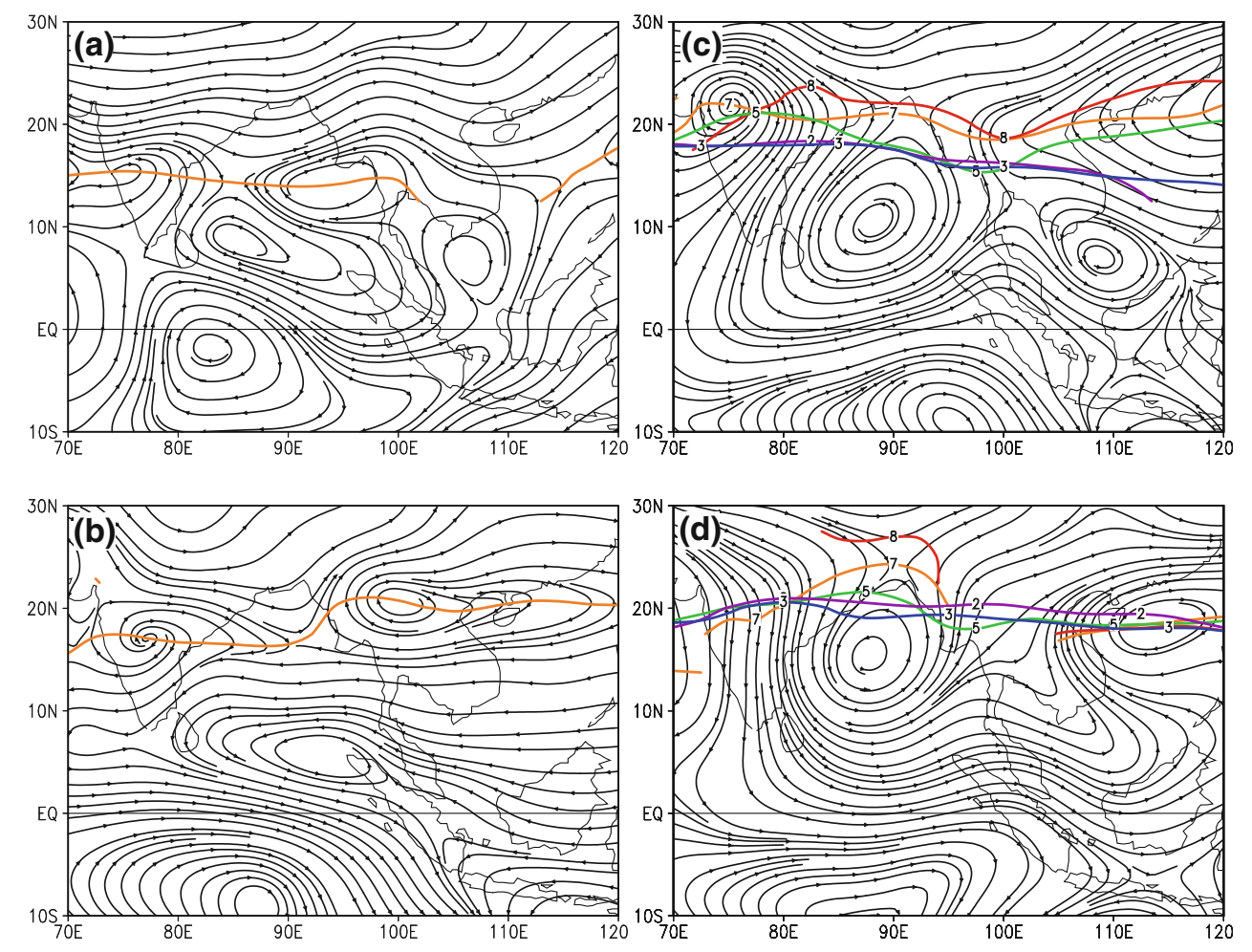
on 13 May before disappearing on 19 May. The wintertime continuous ridgeline of the subtropical anticyclone at $700 \mathrm{hPa}$ was broken by 12 May, followed by the onset of the BOB summer monsoon.

Prior to formation of the vortex, BOB was surrounded by strong surface wind on its southern and western boundaries, with weak wind over the main area of BOB. An offshore ocean current and upwelling were confined to the western coastal BOB, resulting in regional SST cooling. Surface ocean currents are converged from west to east BOB. On the other side, surface anticyclonic circulation and descending air developed over northern BOB, whereas surface cyclonic circulation and ascending air were confined to the south. Because ocean mixing is weak and ocean mixed layer is shallow during this season, intense solar radiation and low surface energy loss acting onto a thin ocead mixed layer in northern BOB resulted in rapid surface warming, and warm SST formed in the eastern part of central $\mathrm{BOB}$, producing a remarkable springtime BOB warm pool.

By early May of 2003, the background conditions of the atmosphere over BOB were favorable for vortex formation. Near the equator, the strong tropical westerly wind brought large amounts of water vapor from Southern Hemisphere and the Arabian Sea eastward to southeastern BOB, from early May. At the same time, water vapor was diverged from the anticyclone over northern $\mathrm{BOB}$ and converged to southeastern BOB. The southeastern BOB is located immediately south of the BOB warm pool, which is an area of stronger surface sensible heating. The convergence of water vapor and the apparent surface sensible heating created favorable conditions for the development of convection in this region, and potential energy was generated and transformed to the kinetic energy required for vortex formation. The spring BOB warm pool and stronger surface sensible heating were located immediately north of the vortex in favor of the generation of available potential energy $\left(\int_{S} Q T d s>0\right)$, meaning that the vortex propagated northward thereafter. During the developing and decaying phases of the vortex over eastern BOB, zonal-mean kinetic energy was transformed to eddy kinetic energy due to the local barotropic instability on the eastern side of the vortex, thereby supplying energy to sustain the vortex and resulting in its eastward movement.

It is clear that the development of a strong southwesterly over the northwestern offshore ocean in BOB is a critical prerequisite for the development of the BOB warm pool and for formation of the monsoon onset vortex. The development of such a strong southwesterly flow in spring season is a consequence of the strong surface thermal forcing of the Indian Subcontinent, induced in turn by Tibetan Plateau forcing. During spring, the Tibetan
Plateau, together with its thermal forcing, generates a cyclonic circulation to its south in the lower troposphere (Wu et al. 2007; Wang and Wu 2008), with a northwesterly prevailing over India and a southeasterly over the Indochina Peninsula. At the end of April, the surface sensible heat flux is weak over the Indochina Peninsula, whereas cold advection over India induces an enhanced land-air temperature difference, resulting in turn in intensification of surface sensible heat release. The strong sensible heat flux $\left(>150 \mathrm{~W} \mathrm{~m}^{-2}\right)$ over India, which is potentially maintained until the end of May, generates strong surface cyclonic circulation. In turn, this results in a strong surface northwesterly along the west coast of India and a strong southwesterly along the east. Given these observations, the generation of the BOB warm pool and BOB summer monsoon onset vortex can be considered as a consequence of air-sea interaction across BOB, modulated by Tibetan Plateau forcing and the land-sea thermal contrast in South Asia during spring, as shown schematically by Fig. 15, which reveals the following features.

(a) In late spring, the atmospheric circulation and climate over South Asia is strongly modulated by the mechanical as well as thermal forcing of the Tibetan Plateau and the land-sea thermal contrast across the area.

(b) The atmospheric forcing thus creates an environment with clear sky, weak surface wind and shallow mixed layer over the central BOB. There strong solar radiation and weak enrgy loss act onto a very thin mixed layer, leading to the generation of a short-life SST warm pool in the eastern part of central BOB.

(c) The BOB warm pool and the associated strong surface sensible heat lease from the ocean in return produce available potential energy in the atmosphere and generate a vortex which leads to the occurrence of earliest Asian monsoon onset over the eastern BOB.

In 2003, the onset vortex moved northward, with intensified surface sensible flux near its center. During its developing and decaying phases, eddy kinetic energy was converted from zonal-mean kinetic energy over the eastern portion of the vortex, and its track turned northeastward. Development of the vortex produced abundant cloud and strong surface wind, reduced the solar radiation on the sea surface, and resulted in enhanced sea surface latent and sensible heat release from the ocean to the atmosphere in the region surrounding the vortex, along with strong mixing and upwelling of cold water in the underlying ocean. These phenomena resulted in a rapid drop in SST within $\mathrm{BOB}$, resulting in turn in gradual decay of the vortex, which by this time was located over northern BOB. The strong southwesterly on the southern and eastern sides of 


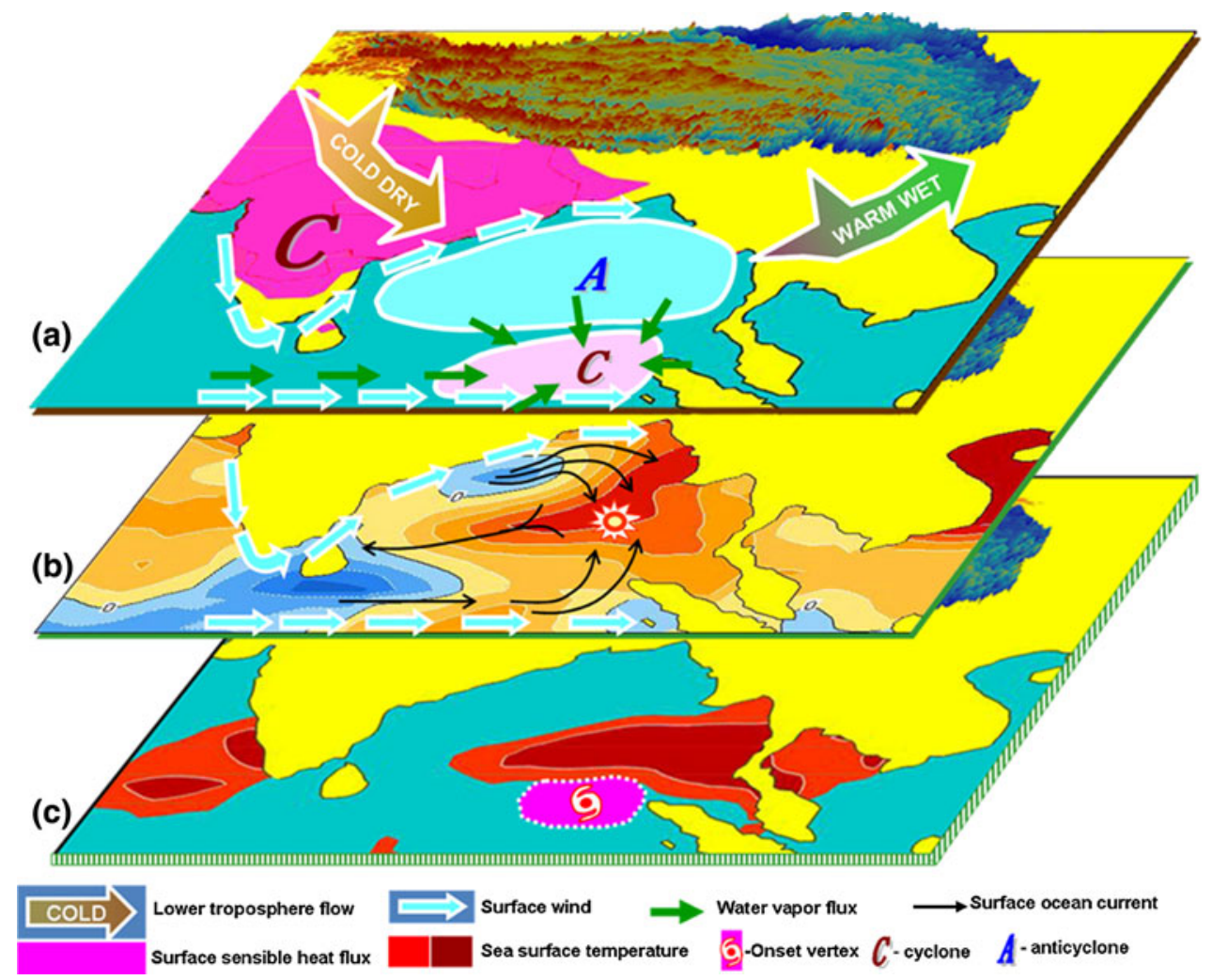

Fig. 15 Schematic diagram showing the formation of the BOB monsoon onset vortex as a consequence of regional air-sea interaction modulated by the land-sea thermal contrast in South Asia and Tibetan Plateau forcing in spring. a Modulation on the atmospheric circulation of the Tibetan Plateau and land-sea thermal contrast in South Asia. The cold and dry northwesterly over India, which is induced by Tibetan Plateau forcing, generates strong surface sensible heating and cyclone circulation. The strong southwesterly along the western offshore region of $\mathrm{BOB}$, combined with the equatorial westerly, force surface anticyclonic circulation with descending air over northern $\mathrm{BOB}$ and cyclonic circulation with ascending air over southern BOB. Large amounts of water vapor are transported from northern BOB and other areas toward southeastern BOB. b Surface ocean current and variation of SST in BOB. The strong southwesterly

the vortex swept over eastern $\mathrm{BOB}$, merging with the subtropical westerly over southern China. Consequently, the wintertime zonally aligned anticyclone belt became broken over eastern $\mathrm{BOB}$, the regional meridional temperature gradient was reversed, and the Asian summer monsoon onset occurred.

The results demonstrated in Fig. 13 present the modulations on the south Asian circulation and climate of the Tibetan Plateau forcing and the land-sea thermal contrast across the tropical Asia. By diagnosing the 1998 case in which the MOV appeared over the southwestern BOB near Sri Lanka, a similar configuration was obtained (Wu et al., 2011). Because this feature is common in spring, therefore the schematic diagram Fig. 15 should be considered as representative. However, the equatorial westerly flow along the western offshore region of BOB results in an offshore current and upwelling, and cold SST is induced along the western BOB. Warm surface water is converged to the eastern part of central $\mathrm{BOB}$, which is under the influence of an anticyclone, with clear sky, weak surface wind and shallow mixed layer. Strong solar radiation together with weak energy loss act onto a very thin mixed layer. Consequently, SST decreases in the west BOB but increases rapidly in the east $\mathrm{BOB}$ prior to the formation of monsoon onset vortex. c Formation of the BOB warm pool and Asian summer monsoon onset vortex. A remarkable springtime warm pool is formed in the eastern part of central BOB just to the north of the surface cyclone, which is marked by strong surface sensible heating. Convection is triggered, and available potential energy is generated and transformed to kinetic energy, thereby generating the $\mathrm{BOB}$ monsoon onset vortex

varies from year to year. Although the flow is rather zonal in 2003, it fluctuated as a disturbed inertial flow along the equator in 1998. Thus, further understanding the variation of the equatorial flow may help in improving the Asian monsoon onset prediction. In addition, air-sea interaction involves many complicated coupling and feedback processes. Given that the present results are based on a case study, they should be considered as preliminary. Nevertheless, the BOB summer monsoon onset vortex occurs in most years, and has a strong influence on the evolution of the Asian monsoon. Furthermore, the track and life cycle of the onset vortex vary among different years, indicating that its influence on monsoon evolution also varies. Therefore, the dynamic mechanism related to the formation and movement of the BOB monsoon onset vortex represents an 
important topic that requires further investigation. In this regard, a high-resolution and coupled modeling study would be very useful to reveal more details of the vortex development.

Acknowledgments We would like to thank the anonymous reviewers for their valuable suggestions. This study was jointly supported by the MOST Program 2010CB950403, CAS program KZCX2-YW-Q11-01, KZCX2-YW-Q11-04, and NSFC Projects 40875034, 40925015, 40821092, and 40810059005.

Open Access This article is distributed under the terms of the Creative Commons Attribution Noncommercial License which permits any noncommercial use, distribution, and reproduction in any medium, provided the original author(s) and source are credited.

\section{References}

Ananthakrishnan R, Srinivasan V, Ramakrishnan AR, Jambunathan R (1968) Synoptic features associated with onset of southwest monsoon over Kerala. In: Forecasting Manual Report No. IV18.2. India Meteorological Department, Pune, India

Ananthakrishnan R, Pathan JM, Aralikatti SS (1981) On the northward advance of the ITCZ and the onset of the southwest monsoon rains over the southeast Bay of Bengal. Int J Climatol $1: 153-165$

Gill AE (1982) Atmosphere-ocean dynamics. Academic Press, London

Gray WM (1968) Global view of the origin of tropical disturbances and storms. Mon Weather Rev 96:669-700

Gray WM (1975) Tropical cyclone genesis. Dept. of Atmospheric Science, Colorado State University, Fort Collins USA, $121 \mathrm{pp}$

Gray WM (1998) The formation of tropical cyclones. Meteor Atmos Phys 67:37-69

Harr PA, Chan JCL (2004) Monsoon impacts on tropical cyclone variability. The third international workshop on monsoons (IWM-III), Hangzhou, China, Secretariat of the World Meteorological Organization, pp 512-542

He JH, Shi XH (2002) Splitting and eastward withdrawal of the subtropical high belt during the onset of the South China Sea summer monsoon and their possible mechanism (in Chinese). J Nanjing Univ (Natural Science) 38:318-330

Hoskins BJ (1991) Towards a PV- $\theta$ view of the general circulation. Tellus (43AB):27-35

Ji M, Leetmaa A, Derber J (1995) An ocean analysis system for seasonal to interannual climate studies. Mon Weather Rev 123(2):460-481

Joseph PV (1990) Warm pool over the Indian Ocean and monsoon onset. Trop Ocean Atmos Newslett 53:1-5

Kanamitsu M, Ebisuzaki W, Woollen J, Yang S-K, Hnilo JJ, Fiorino M, Potter GL (2002) NCEP-DOE AMIP-II reanalysis (R-2). Bull Am Meteor Soc 83:1631-1643

Kershaw R (1985) Onset of the south-west monsoon and sea-surface temperature anomalies in the Arabian Sea. Nature 315:561-563

Kershaw R (1988) Effect of a sea surface temperature anomaly on a prediction of the onset of the southwest monsoon over India. Quart J R Meteor Soc 114:325-345

Krishnamurti TN (1981) Cooling of the Arabian Sea and the onsetvortex during 1979. Recent progress in equatorial oceanography: a report of the final meeting of SCOR WORKING GROUP 47 in Venice, Italy, pp 1-12 [Available from Nova University, Ocean Science Center, Dania, FL 33004]
Krishnamurti TN (1985) Summer monsoon experiment-a review. Mon Weather Rev 113:1590-1626

Krishnamurti TN, Ramanathan Y (1982) Sensitivity of the monsoon onset to differential heating. J Atmos Sci 39:1290-1306

Krishnamurti TN, Ardanuy P, Ramanathan Y, Pasch R (1981) On the onset vortex of the summer monsoon. Mon Weather Rev 109:344-363

Lau KM, Yang S (1997) Climatology and interannual variability of the Southeast Asian summer monsoon. Adv Atmos Sci $14: 141-162$

Lau KM, Wu HT, Yang S (1998) Hydrologic processes associated with the first transition of the Asian summer monsoon: A pilot satellite study. Bull Am Meteor Soc 79:1871-1882

Li C, Yanai M (1996) The onset and interannual variability of the Asian summer monsoon in relation to land-sea thermal contrast. J Clim 9:358-375

Liu Y, Chan JCL, Mao J, Wu G (2002) The Role of Bay of Bengal convection in the onset of the 1998 South China Sea summer monsoon. Mon Weather Rev 130:2731-2744

Liu Y, Wu G, Ren R (2004) Relationship between the subtropical anticyclone and diabatic heating. J Clim 17:682-698

Mak M, Kao CYJ (1982) An instability study of the onset-vortex of the southwest monsoon, 1979. Tellus 34:358-368

Mao J, Wu G (2007) Interannual variability in the onset of the summer monsoon over the eastern Bay of Bengal. Theor Appl Climatol 89:155-170

Mao J, Wu G, Liu Y (2002a) Study on modal variation of subtropical high and its mechanism during seasonal transition Part I: Climatological features of subtropical high structure (in Chinese). Acta Meteor Sin 60(4):400-408

Mao J, Wu G, Liu Y (2002b) Study on modal variation of subtropical high and its mechanism during seasonal transition Part II: seasonal transition index over Asian monsoon region (in Chinese). Acta Meteor Sin 60(4):409-420

Mao J, Chan JCL, Wu G (2004) Relationship between the onset of the South China Sea summer monsoon and the structure of the Asian subtropical anticyclone. J Meteor Soc Jpn 82:845-859

McPhaden M, Hayes S (1991) On the variability of winds, sea surface temperature, and surface layer heat content in the western equatorial Pacific. J Geophys Res 96:3331-3342

Pisharoty PR, Asnani GC (1957) Rainfall around monsoon depressions over India. Indian J Meteor Geophys 8:1-6

Rao KV, Rajamani S (1970) Diagnostic study of a monsoon depression by geostrophic baroclinic model. Indian J Meteor Geophys 21:187-194

Rao RR, Sivakumar R (1999) On the possible mechanisms of the evolution of a mini-warm pool during the pre-summer monsoon season and the genesis of onset vortex in the south-eastern Arabian Sea. Quart J R Meteor Soc 125:787-809

Seetaramayya P, Master A (1984) Observed air-sea interface conditions and a monsoon depression during MONEX-79. Meteor Atmos Phys 33:61-67

Sharma MC, Srinivasan V (1971) Centres of monsoon depressions as seen in satellite pictures. Indian J Meteor Geophys 22:357-358

Shenoi SSC, Shankar D, Shetye SR (1999) On the sea surface temperature high in the Lakshadweep Sea before the onset of the southwest monsoon. J Geophys Res 104:15703-15712

Shenoi SSC, Shankar D, Gopalakrishna VV, Durand F (2005) Role of ocean in the genesis and annihilation of the core of the warm pool in the southeastern Arabian Sea. Mausam 56:147-160

Smith TM, Reynolds RW (2004) Improved extended reconstruction of SST (1854-1997). J Clim 17(12):2466-2477

Uppala SM et al (2005) The ERA-40 reanalysis. Quart J R Meteor Soc 131:2961-3012

Vinayachandran PN, Shankar D, Kuria J, Durand F, Shenoi SSC (2007) Arabian Sea mini warm pool and the monsoon onset vortex. Curr Sci 93:203-214 
Wang TM, Wu G (2008) Land-sea thermal contrast over South Asia and its influences on tropical monsoon circulation (in Chinese). J Tropic Meteor 24:37-43

Webster PJ, Yang S (1992) Monsoon and ENSO: selectively interactive systems. Quart J R Meteor Soc 118:877-926

Webster PJ, Magana VO, Palmer TN, Shukla J, Tomas RA, Yanai M, Yasunari T (1998) Monsoons: processes, predictability, and the prospects for prediction. J Geophys Res 103:14451-14510

Wu G, Liu Y (2000) Thermal adaptation, overshooting, dispersion, and subtropical anticyclone Part I: thermal adaptation and overshooting (in Chinese). Chin J Atmos Sci 24(4):433-446

Wu G, Zhang Y (1998) Tibetan Plateau forcing and the timing of the monsoon onset over South Asia and the South China Sea. Mon Weather Rev 126:913-927

Wu G, Liu Y, Wang T, Wan R, Liu X, Li W, Wang Z, Zhang Q, Duan A, Liang X (2007) The influence of the mechanical and thermal forcing of the Tibetan Plateau on the Asian climate. J Hydrometeor 8:770-789

Wu G, Liu Y, Zhu X, Li W, Ren R, Duan A, Liang X (2009) Multiscale forcing and the formation of subtropical desert and monsoon. Ann Geophys 27:3631-3644

Wu GX, Guan Y, Wang TM, Liu YM, Yan JH, Mao JY (2011) Vortex genesis over the Bay of Bengal in spring and its role in the onset of the Asian Summer Monsoon. Sci China 54(1):1-9

Yan JH (2005) Asian summer monsoon onset and advancing process and the variation of the Subtropical High. Dissertation, Graduate University of Chinese Academy of Sciences, Beijing

Zhang HM, Bates JJ, Reynolds RW (2006) Assessment of composite global sampling: Sea surface wind speed. Geophys Res Lett 33(17):L17714 